MEISAM NASROLLAHI, Ph.D. Candidate ${ }^{1}$

E-mail: m_nasrollahi@ut.ac.ir

JAFAR RAZMI, Prof. ${ }^{1}$

E-mail: jrazmi@ut.ac.ir

REZA GHODSI, Prof. ${ }^{1}$

(Corresponding author)

E-mail: ghodsi@ut.ac.ir

1 School of Industrial Engineering

College of Engineering, University of Tehran

Kargar Shomali St, Tehran, Iran
Traffic and Environment (Ecology)

Original Scientific Paper

Submitted: 21 Oct. 2017

Accepted: 10 July 2018

\title{
A COMPUTATIONAL METHOD FOR MEASURING TRANSPORT RELATED CARBON EMISSIONS IN A HEALTHCARE SUPPLY NETWORK UNDER MIXED UNCERTAINTY: AN EMPIRICAL STUDY
}

\begin{abstract}
Measuring carbon emissions is an essential step in taking required action to fight global warming. This research presents a computational method for measuring transport related carbon emissions in a healthcare supply network. The network configuration significantly impacts carbon emissions. First, a multi-objective mathematical programing model is developed for designing a healthcare supply network in the form of a two-graph location routing problem under demand and fuel consumption uncertainty. Objective functions are minimizing total cost and minimizing total fuel consumption. In the presented model, the demand of each customer must be completely satisfied in each time period, and backlog is not permitted. The number and capacity of vehicles are determined, and vehicles are heterogeneous. Furthermore, fuel consumption depends on traveling distance, vehicle and road conditions, and the load of a vehicle. The centroid method is applied to face demand uncertainty. Next, a multi-objective non-dominated ranked genetic algorithm (M-NRGA) is proposed to solve the model. Then, a Monte Carlo based approach is presented for measuring transport-related carbon emissions based on fuel consumption in supply network. Finally, the proposed approach is applied to the case of a healthcare supply network in the Fars province in Iran. The obtained results illustrate that the proposed approach is a practical tool in designing healthcare supply networks and measuring transport-related carbon emissions in the network.
\end{abstract}

\section{KEY WORDS}

healthcare; greenhouse effect; supply network; carbon emissions; Monte Carlo;

\section{INTRODUCTION}

Environmental changes and global warming are among the most important challenges humans have faced in the last hundred years [1, 2]. Earth system simulation shows that the current trend of greenhouse gas emissions may affect most ecosystems and the lives of over 3.5 billion people worldwide as early as 2050 [3]. Carbon dioxide $\left(\mathrm{CO}_{2}\right)$ and carbon monoxide (CO) are the primary greenhouse gases emitted through human activities. As the most important cause of long-term climate change, carbon emissions provide a good baseline to assess progress and evaluate the consequences. The current emission trends continue to follow scenarios that lead to the highest global temperature increases [4]. Carbon emissions produced by human activities usually come from burning fossil fuels, e.g. oil, natural gas, coal, and wood [5].

To overcome this challenge, governments and industry sectors are working to understand their own carbon footprint and explore the required actions. Reducing the global temperature and associated climate change impacts can be achieved by decreasing the emissions of greenhouse gases as soon as possible [6]. The experiences of the largest global corporations as well as those of start-up companies indicate how these companies can profitably reduce greenhouse gas emissions in their supply chains [7]. Approximately $45 \%$ of greenhouse gas emissions is caused by production and transportation of goods [8]. Hence, it is important to restrict such emissions in a supply network.

In the past decades, many researchers have focused on modeling the uncertainty in designing supply networks. For this aim, different stochastic modeling approaches have been successfully applied to supply chain production planning problems considering the randomness concept. However, in some applications, the probability distributions are not available or reliable [9]. On the other hand, in some real applications, the nature of retailer's demand is imprecise. In this case, fuzzy set theory (FST) provides a proper 
framework for handling uncertainty or vagueness in a dataset. In decision sciences, fuzzy set theory has a great impact on preference modeling and multi-criteria assessment by taking into account the user needs in optimization techniques [10]. Hence, in the proposed method, trapezoidal fuzzy numbers are used to characterize the fuzzy demand for products, vehicle performance, and road conditions. Note that in most real applications of a supply chain problem there is not enough historical data for the previous demand values. In these cases, using fuzzy numbers can be used to describe the decision models for the external demand of a network. Although there is no conclusive methodology for measuring carbon emissions at present $[11,12]$, this research provides a computational method for measuring transport related carbon emissions (TRCE) in a supply network. First, a mathematical model to design proper supply network is developed, and then a computational method is proposed for measuring TRCE in this network, based on the Monte Carlo approach. In Section 2, a literature overview of supply network design and measuring carbon emissions is given. The mathematical model to design the supply network is presented in Section 3, followed by the solution approach and TRCE measuring approach. The case study, i.e., Fars healthcare supply network, is presented in Section 5. At the end, the conclusion and future study considerations finalize the paper.

\section{LITERATURE REVIEW}

Generally, the causes of carbon emissions can be divided into natural and human sources. The main carbon emissions due to human activities includes industries like cement and electricity production, commercial and residential causes, deforestation, agriculture, and transportation. Also, the major carbon footprint applications in the UK can be categorized by seven areas, including national emissions inventories and trade, emission drivers, economic sectors, supply chains, organizations, household consumption and lifestyles, as well as sub-national emission inventories. Researchers in $[8,13]$ state that to restrict the emissions of greenhouse gases, companies should take into account their business practices and operational policies along with focusing on their physical processes (inefficient equipment and facilities, redesigning products and packaging, finding less polluting sources of energy, or instituting energy saving programs). They attempted to explore how operational decisions across the supply chain affect the carbon footprint of these supply chains and the extent to which concerns about carbon emissions are covered by adjusting operational decisions and improving collaboration among supply chain partners. They also showed how carbon emission concerns can be integrated into operational decision-making with regard to procurement, production, and inventory management using relatively simple and widely used models.

The transportation of goods accounts for a large amount of carbon releasing all over the world. TRCE cannot be measured easily because of the large amount of data required and the use of different standards for carbon footprint calculation [14]. Several researchers proposed various methods for computing carbon emissions in a supply chain [15-20]. For instance, they calculated the carbon footprint of different feedstock for dairy cattle by applying life cycle assessment (LCA) [18]. Others proposed a fast and vigorous technique applying a novel approach based upon multi-gene genetic programming (MGGP) to determine carbon dioxide minimum miscibility pressure $\left(\mathrm{CO}_{2} \mathrm{MMP}\right)$ for carbon dioxide injection processes [19]. In [20], a "corrected average emission model" was provided, i.e., an improved average speed model that accurately computed $\mathrm{CO}_{2}$ emissions on the road.

Transportation consumes energy severely worldwide and is overwhelmingly oil-oriented. For this reason, TRCE is one of the main sources of global carbon emissions and also contributes to air quality concerns, particularly in and around major population centers [21]. In this regard, [22] showed that most of the imported oil in the USA is consumed only in the transportation sector. Additionally, one third of total greenhouse gas (GHG) emissions is produced by this sector. For reducing GHG emissions and oil consumption, different policy scenarios must be considered in the US transportation sector. Therefore, proper green transportation network design is a suitable solution for decreasing carbon emission [23], [24].

Recently, in the period of global competition, the network design has been considered as one of the strategic decision problems. A network design problem focuses on the number and locations of raw material suppliers, manufacturing plants, and inventory warehouses. In an extended time horizon, the decisions in this regard include selecting the distribution channel from suppliers to customers as well as determining the transportation volume among distributed facilities [25]. The supply network design problem is well documented in the literature, and the readers are referred to the review the paper [26].

The vehicle routing problem (VRP) is the problem of designing routes for delivery vehicles with known capacities operating from a single depot to supply a number of customers with known locations and known demands for a certain commodity. Vehicle routes are designed to minimize several objectives, like the total distance traveled [27]. For instance, the authors in [28] presented a new mathematical model in order to measure and evaluate the efficiency of the periodic vehicle routing problem (PVRP) in a competitive environment. A general model for dynamic vehicle routing 
problem with time windows (DVRPTW) considering the minimization of the total distance as the main objective was presented in [29]. A review paper highlighted major exact algorithms in the VRP literature [30]. They focused on mathematical formulations, relaxations, and recent exact methods for two main VRP variants, including the capacitated VRP (CVRP) and the VRP with time windows (VRPTW). For detailed information about VRP, please refer to the review paper [30].

As one type of the network design problem, the location routing problem (LRP) deals with the combination of both the facility location problem (FLP) and the vehicle routing problem (VRP). Since these two categories of problems belong to the class of NP-hard problems, the LRP is also an NP-hard problem. In the LRP, the entire consumer demand should be satisfied in such a way that a facility's operating and fixed costs are minimized while vehicle capacities must be considered and routing costs must be reduced simultaneously [31]. Several researchers have developed heuristic and meta-heuristic algorithms for LRP [32-34]. A new heuristic algorithm for the capacitated location routing problem (CLRP) was presented in [35], called granular variable tabu neighborhood search (GVTNS). In order to solve the periodic location routing problem (PLRP), a large neighborhood search (LNS) algorithm was presented in [36].

Recently, researchers and practitioners have taken into account the environmental concerns in designing supply networks. In this respect, decisions on supply chain design have to be integrated with those related to environmental concerns. In other words, a green supply chain network design problem contains an initial investment into environmental protection equipment or techniques to ensure its long-term benefit to environmental indicators [37]. Fortunately, due to the importance of the green supply chain concept, a lot of research has been focused on this area. Please see the comprehensive survey provided by [38] for more detailed information. Most research on designing a green supply network has considered a deterministic behavior for the supply network. However, in most practical situations, we may face numerous sources of technical and/or commercial uncertainty in the design phase.

The concept of uncertainty in LRP problems is considered in several studies [33], [39-43]. The authors in [44] described the impact of network type on uncertainty in demand estimation. They suggested that the configuration of the network can affect the final accumulation of uncertainty in the supply chain. The authors in [45] identified the impact of the accumulation of individual delivery time uncertainties on overall delivery time uncertainty. Also, they stated that the type of network and their structures have a significant influence on delivery time uncertainty. In order to prove their idea, they created a probabilistic technique for measuring and evaluating that impact by using the Markov theorem.

In this paper, we simultaneously take into account the environmental concerns and uncertainty conditions in a healthcare supply network. A multi-objective non-dominated ranked genetic algorithm (M-NRGA) is proposed to solve the developed multi-objective mathematical model. A Monte Carlo based approach is presented to measure transport-related carbon emissions based on fuel consumption in a supply network. We also represent the application of the proposed approach to the case of the healthcare supply network in the Fars province in Iran.

\section{PROBLEM DEFINITION}

\subsection{Healthcare supply network}

In the presented healthcare supply network, a number of distribution centers should be located among candidate sites. Furthermore, delivery routes between the central depot and these distribution centers as well as delivery routes for a set of customers must be established in such a way that the total system cost is minimized. Therefore, the network configuration includes a two-graph location routing problem. In one graph, a fleet of vehicles with known capacities is operating from a central depot to supply a number of distribution centers which should be located among candidate sites. All vehicle routes start and end at the central depot. The demand of each distribution center must be completely satisfied, and backlog is not permitted. All distribution centers are visited exactly once by exactly one vehicle in each time period, so split delivery is not permitted. The sum of distribution centers' demand for any vehicle route may not exceed vehicle capacity. In the other graph, the network configuration is a multi-depot vehicle routing problem in which a fleet of vehicles with known capacities operate from a central depot to supply a number of customers with known locations. Each vehicle route starts and ends at the same distribution center. The demand of each customer must be completely satisfied, and backlog is not permitted. All customers are visited exactly once by exactly one vehicle in each time period, so split delivery is not permitted; the sum of customers' demand for any vehicle route may not exceed the vehicle capacity. A direct delivery from the central depot to the customers is not permitted, as well as a delivery from one distribution center to the other. In summary, we face a two-graph location routing problem, i.e., to simultaneously determine the number and locations of distribution centers, assignment of customers to distribution centers, and vehicle routes. Figure 1 illustrates the healthcare supply network. In the proposed model, there are multiple time periods in the planning 


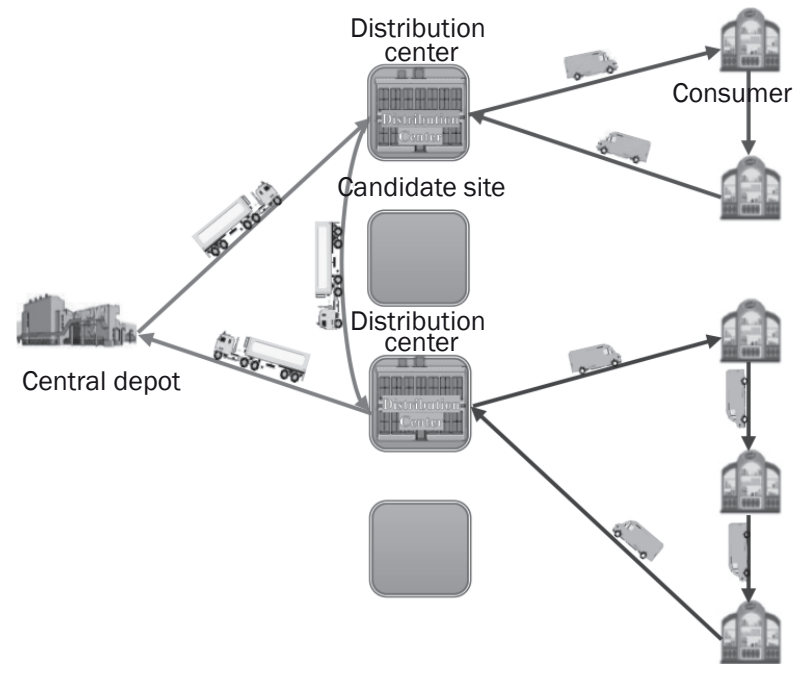

Figure 1 - Healthcare supply network

horizon. The customers' demand for each product is a trapezoidal fuzzy number $\left(\tilde{d}=\left(d_{1}, d_{2}, d_{3}, d_{4}\right)\right.$ where: $d_{1} \leq d_{2} \leq d_{3} \leq d_{4}$ ) on $\mathbb{R}$ ). The membership function of the trapezoidal fuzzy number is presented in Equation 1 [46].

$\mu_{\tilde{d}}(x)=\left\{\begin{array}{lc}\frac{x-d_{1}}{d_{2}-d_{1}} & d_{1}<x<d_{2} \\ 1 & d_{2}<x<d_{3} \\ \frac{d_{4}-x}{d_{4}-d_{3}} & d_{3}<x<d_{4} \\ 0 & \text { Otherwise }\end{array}\right.$

In Equation 1, if $d_{2}=d_{3}$, then $\tilde{t}$ is a triangular fuzzy number. Also, if $d_{1}=d_{2}=t_{3}=t_{4}$, then $\tilde{t}$ is a crisp number. Figure 2 illustrates the membership function of the trapezoidal fuzzy number.

The number and capacity of vehicles and candidate locations for distribution centers are determined. Vehicles are heterogeneous and can take only one tour in each time period. The objectives are minimizing the total cost of the system and minimizing total fuel consumption. Fuel consumption depends on traveling distance, vehicle and road conditions, and the load of a vehicle. All of these quotients are trapezoidal fuzzy numbers.

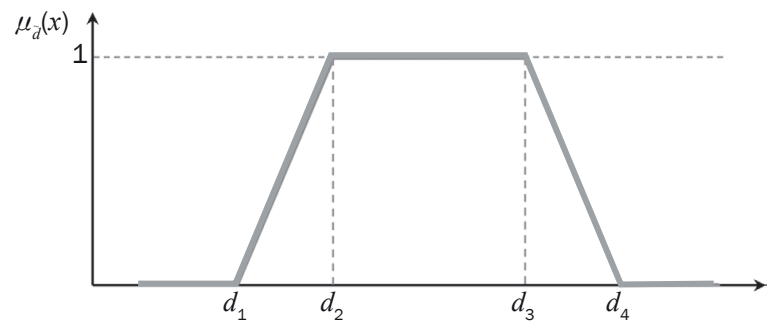

Figure 2 - Membership function of the trapezoidal fuzzy number

\section{Assumptions}

- The selection of the central depot and customers' location is beyond the scope of this paper, but the locations of distribution centers are determined by the presented model

- The vehicles are heterogeneous

- Split delivery is not permitted

- The capacities of distribution centers and vehicles are definite

- The routing process is performed between customer - distribution center echelons and central depot - distribution center echelons. Hence, the VRP is a multi-graph problem.

- It is not possible to stock pharmaceutical substances for future periods in distribution centers

- Demand is considered to be uncertain

- Fuel consumption per distance unit is considered to be uncertain

- Fuel consumption per load unit is considered to be uncertain

- Time windows for distribution centers and customers are not considered.

\subsection{Mathematical model for healthcare supply network design}

The proposed mathematical programing formulation is presented below:

Sets:

$I$ - Set of customers indexed by $i=1,2, \ldots, N$; where $N$ is the number of customers

$J$ - Set of candidate locations indexed by $j=0,1,2, \ldots, P$; where $P$ is the number of candidate locations. 0 is the central depots index

$G$ - Set of all supply network graph nodes $G=I \cup J=\{0,1,2, \ldots, P, P+1, \ldots, P+N\}$

$A$ - Set of $\operatorname{arcs}(i, j)$

$T$ - Set of time periods indexed by $t=1,2, \ldots, K$; where $K$ is the number of time periods in the planning horizon

$M$ - Set of products indexed by $m=1,2, \ldots, M$; where $M$ is the number of products distributed in the supply network

$V$ - Set of vehicles indexed by $v=1,2, \ldots, V$; where $V$ is the number of available vehicles

Parameters:

$\tilde{d}_{i m}^{t}$ - Customer $i$ demand for product $m$ in the period $t$

$\xi_{j}$ - Fixed cost for opening a distribution center in the candidate location $j$

$\zeta_{v}$ - Fixed cost for using vehicle $v$

$\gamma_{i j}$ - The distance along the arc $(i, j) \in A$

$\varpi_{i j}^{v}$ - Traveling cost per distance unit for vehicle $v$ in $\operatorname{arc}(i, j) \in A$

$\alpha_{j}^{m}$ - The capacity of distribution center placed in node $j$ for the product $m$. Capacity of central depot $\left(\alpha_{0}^{m}\right)$ is infinitive for all products. 
$\beta_{v}^{m}$ - Capacity $v$-th vehicle for product $m$

$\vartheta_{m}$ - Weight of each unit of product $m$

$\tilde{\omega}_{0}^{v}$ - Fuel consumption per distance unit for unloaded vehicle $v$ in a road without slope

$\tilde{\omega}_{1}^{v}$ - Additional fuel consumption per distance unit for vehicle $v$ associated with load unit

$\tilde{\omega}_{2}^{v}$ - Quotient of fuel consumption per distance unit for vehicle $v$ associated with vehicle conditions

$\tilde{\omega}_{3}^{i j v}$ - Quotient of fuel consumption per distance unit for vehicle $v$ associated with road conditions $(\operatorname{arc}(i, j) \in A)$

Decision variables:

$X_{i j}^{v t}-1$ if vehicle $v$ at time period $t$ travels in arc $(i, j) \in A$, and 0 otherwise

$Y_{i j}^{t}-1$ if in time period $t$ the demand of customer $i$ is satisfied by the distribution center placed in node $j$, and 0 otherwise

$Z_{j} \quad-1$ if a distribution center open at candidate location $j$, and 0 otherwise

$\tilde{L}_{i j}^{v t}$ - Load of vehicle $v$ traveling $\operatorname{arc}(i, j) \in A$ at time period $t$

$U_{i v}^{t}$ - Auxiliary variable for sub-tour elimination constraints in vehicle $v$ route

$U_{i v}^{t}$ - Auxiliary variable for sub-tour elimination constraints in vehicle $v$ route

Objective functions:

$$
\begin{aligned}
\min Z_{1}= & \sum_{\forall j} \xi_{j} Z_{j}+\sum_{j \in J} \sum_{v \in V} \sum_{t \in T} \zeta_{v} X_{0 j}^{v t}+ \\
& +\sum_{i \in I} \sum_{j \in J} \sum_{\substack{v \in V \\
j \neq 0}} \sum_{t \in T} \zeta_{v} X_{i j}^{v t}+ \\
& +\sum_{i \in G} \sum_{j \in G} \sum_{v \in V} \sum_{t \in T} \varpi_{i j}^{v} \gamma_{i j} X_{i j}^{v t}
\end{aligned}
$$

$$
\min Z_{2}=\sum_{i \in G} \sum_{j \in G} \sum_{v \in V} \sum_{t \in T}\left(\tilde{\omega}_{0}^{v}+\tilde{\omega}_{1}^{v} \tilde{L}_{i j}^{v t}+\tilde{\omega}_{2}^{v}+\tilde{\omega}_{3}^{i j v}\right) \gamma_{i j} X_{i j}^{v t}
$$

Subject to:

$$
\begin{aligned}
& \sum_{i \in I} \tilde{d}_{i m}^{t} Y_{i j}^{t} \leq a_{j}^{m} Z_{j} \quad \forall j \in J ; \forall m \in M ; \forall t \in T \\
& \tilde{d}_{j m}^{t}=\sum_{i \in I} \tilde{d}_{i m}^{t} Y_{i j}^{t} \quad \forall j \in J ; \forall m \in M ; \forall t \in T \\
& \sum_{i \in G} \sum_{j \in G} \tilde{d}_{i m}^{t} X_{i j}^{v t} \leq \beta_{v}^{m} \quad \forall m \in M ; \forall v \in V ; \forall t \in T \\
& \sum_{\substack{i \in G \\
j \neq 0}} \sum_{v \in V} X_{i j}^{v t} \leq 1 \quad \forall i \in I ; \forall t \in T \\
& \sum_{i \in G} \sum_{v \in V} X_{i j}^{v t} \leq 1 \quad \forall j \in J ; \forall t \in T \\
& \sum_{i \in G} \sum_{j \in G} X_{i j}^{v t} \leq 1 \quad \forall v \in V ; \forall t \in T \\
& \tilde{L}_{0 j}^{v t}=\sum_{i} \sum_{j} \sum_{m \in M} \tilde{d}_{j m}^{t} \vartheta_{m} X_{0 j}^{v t} \quad \forall v \in V ; \forall t \in T \\
& \tilde{L}_{j i}^{v t}=\sum_{i} \sum_{j, j \neq 0}^{j \neq 0} \sum_{m \in M} \tilde{d}_{i m}^{t} \vartheta_{m} X_{i j}^{v t} \quad \forall v \in V ; \forall t \in T \\
& \sum_{j \in G} X_{i j}^{v t} \tilde{L}_{i j}^{v t}-\sum_{j \in G} X_{j i}^{v t} \tilde{L}_{j i}^{v t}=\sum_{j \in G} X_{i j}^{v t} \tilde{d}_{j m}^{t} \vartheta_{m} \\
& \forall i \in G ; \forall v \in V ; \forall t \in T \\
& U_{l v}^{t}-U_{i v}^{t}+N X_{l i}^{v t} \leq N-1 \quad \forall l \in I ; \forall i \in I ; \forall v \in V ; \forall t \in T
\end{aligned}
$$

$$
\begin{aligned}
& U_{k v}^{t}-U_{j v}^{t}+N X_{k j}^{v t} \leq P-1 \\
& \forall k \in J ; j \in J \& \neq 0 ; \forall v \in V ; \forall t \in T \\
& \sum_{j \in G} X_{i j}^{v t}-\sum_{j \in G} X_{j i}^{v t}=0 \quad \forall i \in G ; \forall v \in V ; \forall t \in T \\
& \sum_{k \in I} X_{j k}^{v t}+\sum_{k \in I} X_{k i}^{v t} \leq Y_{i j}^{t}+1 \\
& X_{i j}^{v t} \in\{0,1\} \\
& Y_{i j}^{t} \in\{0,1\} \\
& Z_{j} \in\{0,1\} \\
& \tilde{L}_{i j}^{v t} \geq 0 \\
& U_{i v}^{t} \in\{N \cup 0\} \\
& U_{i v}^{t} \in\{P \cup 0\}
\end{aligned}
$$

Objective function 2 shows the sum of fixed costs of opening distribution centers in candidate locations, the sum of fixed costs for using vehicles at the central depot, the sum of fixed costs for using vehicles at distribution centers, and transportation costs. Objective function 3 represents fuel consumption considering traveling distance, vehicle and road conditions, and the load of a vehicle.

Constraint 4 assures customers are allocated to distribution centers within their capacity. Constraint 5 states that the demand of distribution center $j$ is equal to sum of the demands of customers which are allocated to distribution center $j$. Constraint 6 ensures that customers are visited within vehicle capacity. Constraints 7 and 8 ensure that all customers and all distribution centers are visited once in each time period. Constraint 9 states that each vehicle can take only one tour in each time period. Constraints 10, 11, and 12 show the load of vehicles at each route. Sub-tour elimination in both graphs is assured in Constraints 13 and 14. The continuity of tours and returning the vehicle to the origin depot is ensured in Constraint 15. Constraint 16 states that customer can be allocated to a distribution center and distribution center can be allocated to central depot only if there is a route connected to them. The binary variables are defined in Constraints 17,18 , and 19 . Finally, load and auxiliary variables taking positive values are declared in Constraints 20, 21, and 22.

\section{SOLUTION APPROACH}

The solution approach is presented in 3 steps. First, we present an approach for facing uncertainty; then we describe a method for solving the proposed optimization model for the network design problem; and, finally, we propose a Monte Carlo approach based approach for measuring TRCE. 
In this paper, the centroid method is applied for the defuzzification of the trapezoidal fuzzy number. The centroid of the trapezoidal fuzzy number $\tilde{t}$ is shown in Equation 23 [47].

$C_{\tilde{t}}=\frac{t_{3}^{2}+t_{4}^{2}+t_{3} t_{4}-t_{1}^{2}-t_{2}^{2}-t_{1} t_{2}}{3\left(t_{3}+t_{4}-t_{1}-t_{2}\right)}$

\subsection{Solution algorithm}

To solve the proposed model, we developed a twophase algorithm based on non-dominated ranked genetic algorithm for solving multi-objective optimization problems (NRGA) and preference ranking organization method for enrichment of evaluations (PROMETHEE). In the first phase, the Pareto front is generated by NRGA; in the second phase, the best solution is determined by the PROMETHEE-II method.

NRGA was developed by Al Jadaan et al. [48]. In this paper, we develop a modified version of the multi-objective NRGA called M-NRGA. In NRGA, a two-phase selection method is implemented. In the first phase, one of the fronts is selected by a fitness proportionate selection procedure (roulette wheel) based on its rank, and in the next phase one chromosome is selected from this front. Therefore, in NRGA the possibility of selecting a chromosome depends on its front's rank [49]. In the proposed M-NRGA, to improve the quality of the solutions in the Pareto front, $P_{e}$ percent of solutions are selected based on elitism from the elitist solutions in the first front. In addition, to increase the diversity of the solutions in the Pareto front, $P_{t}$ percent of solutions are selected based on the tournament method. In the proposed M-NRGA, since $P_{e}$ percent of solutions are selected based on elitism, it is possible to adjust the number of solutions in the Pareto front to be at least equal to a fixed number. The proposed M-NRGA, as described, is as follows:

1) Initialize the first generation of solutions randomly with the population size $N$.

2) Calculate both objective functions for all solutions.

3) Sort and locate the solution based on the method presented in [48].

4) Do the crossover operation for $P_{c}$ and mutation for $P_{m}$ presentation of population.

5) Select $N$ solution for the next generation. Three strategies are applied to select the solutions:

a) $P_{e}$ percent of solutions are selected based on elitism from the elitist solutions in the first front.

b) $P_{t}$ percent of solutions are selected based on the tournament method. Two solutions are selected randomly. The one that belongs to the front with the higher rank wins. If the solutions come from the same front, the one with the higher rank in the front wins.

c) $P_{r}$ percent of solutions are selected based on the roulette wheel method. At first, the front is selected with the probability of $P_{F}$, as shown in Equation 24, and then the solution is selected with the probability of $P_{r}$ from the selected front, as presented in Equation 25.

$$
\begin{aligned}
& P_{F}=\frac{\operatorname{Rank}_{F}}{\frac{N F}{2}(N F+1)} \\
& P_{r}=\frac{\operatorname{Rank}_{S F}}{\frac{N S F_{F}}{2}\left(N S F_{F}+1\right)}
\end{aligned}
$$

where $N F$ is the number of fronts, Rank $_{F}$ is the rank of front $F, N S F_{F}$ is the number of solutions in front $F$, and $\operatorname{Rank}_{s F}$ is the rank of solution $s$ in front $F$.

6) If the end condition is satisfied, the solution approach is over, otherwise go back to step 3 .

In the second phase, the best solution is identified by PROMETHEE-II from the best Pareto front obtained in the previous phase. The PROMETHEE was first developed by Brans and Vincke in 1985 [50]. PROMETHEE-I can provide a partial ranking, while PROMETHEE-II can drive total ranking of the solutions. Therefore, in this paper, we use PROMETHEE-II. The method we applied is exactly as it described in [51].

\subsection{Measuring TRCE}

Measuring TRCE based on fuel consumption is not a straightforward processs. The amount of carbon emission depends on many factors such as the quality of fuel, vehicle conditions, weather conditions, the load of vehicle, etc. Therefore, in the mathematical formulation based on fuel consumption for TRCE, the carbon emission quotient is a probabilistic parameter. Due to Equation 3, TRCE can be measured by Equation 26.

$$
\begin{aligned}
& \text { TRCE }= \\
& =\hat{\psi}\left[\sum_{i \in G} \sum_{j \in G} \sum_{v \in V} \sum_{t \in T}\left(\tilde{\omega}_{0}^{v}+\tilde{\omega}_{1}^{v} \tilde{L}_{i j}^{v t}+\tilde{\omega}_{2}^{v}+\tilde{\omega}_{3}^{i j v}\right) \gamma_{i j} X_{i j}^{v t}\right]
\end{aligned}
$$

where $\hat{\psi}$ is a probabilistic parameter probability density function $f(y)$ for the carbon emission quotient. The cumulative distribution function $F_{Y}$ is defined as Equation 27.

$F_{Y}=\int_{-\infty}^{y} f(y) d y$

To calculate TRCE, we applied a Monte Carlo based approach. The suggested algorithm is as follows:

1) Estimate the probability density function for carbon emission quotient $(\hat{\psi})$.

2) Create a vector with $B$ array for each probabilistic and fuzzy number in Equation 26 considering their probability density function or fuzzy membership function.

3) Calculate TRCE vector by Equation 28. 


$\begin{array}{cccccc}\hat{\psi} & \widetilde{\omega}_{0}^{v} & \widetilde{\omega}_{1}^{v} & \tilde{L}_{3}^{i j v} & \widetilde{\omega}_{2}^{v} & \widetilde{\omega}_{3}^{i j v} \\ & \forall v & \forall v & \forall i, j \& v & \forall v & \forall i, j \& v\end{array}$

$$
\left[\begin{array}{c}
\psi_{1} \\
\psi_{2} \\
\vdots \\
\psi_{B}
\end{array}\right] \quad\left[\begin{array}{c}
\omega_{0_{1}}^{v} \\
\omega_{0_{2}}^{v} \\
\vdots \\
\omega_{0_{B}}^{v}
\end{array}\right] \quad\left[\begin{array}{c}
\omega_{1_{1}}^{v} \\
\omega_{1_{2}}^{v} \\
\vdots \\
\omega_{1_{B}}^{v}
\end{array}\right] \quad\left[\begin{array}{c}
L_{3}^{i j v}{ }_{1} \\
L_{3}^{i j v}{ }_{2} \\
\vdots \\
L_{3}^{i j v}{ }_{B}
\end{array}\right] \quad\left[\begin{array}{c}
\omega_{2_{1}}^{v} \\
\omega_{2}^{v} \\
\vdots \\
\omega_{2_{B}}^{v}
\end{array}\right] \quad\left[\begin{array}{c}
\omega_{3}^{i j v}{ }_{1} \\
\omega_{3}^{i j v}{ }_{2} \\
\vdots \\
\omega_{3}^{i j v}{ }_{B}
\end{array}\right]
$$

Figure 3 - Vectors for probabilistic and fuzzy numbers

$$
\begin{aligned}
{\left[\begin{array}{c}
T R C E_{1} \\
T R C E_{2} \\
\vdots \\
T R C E_{B}
\end{array}\right]=} & {\left[\begin{array}{c}
\psi_{1} \\
\psi_{2} \\
\vdots \\
\psi_{B}
\end{array}\right] \cdot\left(\sum _ { i \in G } \sum _ { j \in G } \sum _ { v \in V } \sum _ { t \in T } \gamma _ { i j } X _ { i j } ^ { v t } \left(\left[\begin{array}{c}
\omega_{01}^{v} \\
\omega_{02}^{v} \\
\vdots \\
\omega_{0 B}^{v}
\end{array}\right]\right.\right.} \\
& \left.\left.+\left[\begin{array}{c}
\omega_{11}^{v} \\
\omega_{12}^{v} \\
\vdots \\
\omega_{1 B}^{v}
\end{array}\right] \cdot\left[\begin{array}{c}
L_{31}^{i j v} \\
L_{32}^{i j v} \\
\vdots \\
L_{3 B}^{i j v}
\end{array}\right]+\left[\begin{array}{c}
\omega_{21}^{v} \\
\omega_{22}^{v} \\
\vdots \\
\omega_{2 B}^{v}
\end{array}\right]+\left[\begin{array}{c}
\omega_{31}^{i j v} \\
\omega_{32}^{i j v} \\
\vdots \\
\omega_{3 B}^{i j v}
\end{array}\right]\right)\right)
\end{aligned}
$$

4) Calculate average and variance of resulted vector. That would present the average and variance of TRCE.

5) Draw the histogram of the transpose of resulted vector. From the sampling frequency of $\left[T R C E_{1}, T R C E_{2}, \ldots, T R C E_{B}\right]$, the probability density function of TRCE can be obtained.

\section{CASE STUDY}

\subsection{Fars healthcare supply network}

In this paper, Fars healthcare supply network is considered as the case study. Fars is one of the thirty-one provinces of Iran and located in the south of the country. Fars has one of the richest cultural heritages in Iran, encompassing many disciplines such as literature, poetry, architecture, and stonemasonry, and it is known as the cultural capital of Iran. In 2015, this province had a population of 4.6 million people [52]. Due to the capabilities of Fars healthcare industry, such as a remarkable number of hospitals, reputable physicians, high quality healthcare services, mild weather, tourist attractions, and good hotels, many patients from all over Iran, the Persian Gulf countries, and even Europe travel to Shiraz to receive healthcare services.

We consider five years as the planning horizon for the Fars healthcare supply network divided into 60 one-month periods. In the Fars healthcare supply network, as illustrated in Figure 4, the central depot is located in Shiraz. Shiraz is the capital city of the Fars province and the most populous city in the south of
Iran with the population of 1.9 million [52]. There are 29 customers and 5 candidate locations for distribution centers in Shiraz, Fasa Eqlid, Firuzabad, and Lar. The distances between network nodes are given in Table 1. In this supply network, 2,447 types of products are distributed. The demand for each product is estimated based on recent 36-month demand. The total demand for all products in Fars is 2,405,281,094 annually. We used Equation 23 to calculate the centroid of demands $\left(C_{\tilde{d}_{i m}^{t}}^{t}\right)$. Some of the results are given in Table 2. Obviously, these 2,447 types of products increase the problem complexity unnecessarily. In order to simplify the problem, we classified the pharmaceutical substances into 47 major groups, as shown in Table 3.

Three different meta-heuristic algorithms, including NSGA-II, MOPSO, and the proposed M-NRGA, are used to solve the proposed optimization model for the network design problem. NSGA-II is one of the most popular multi-objective evolutionary algorithms,

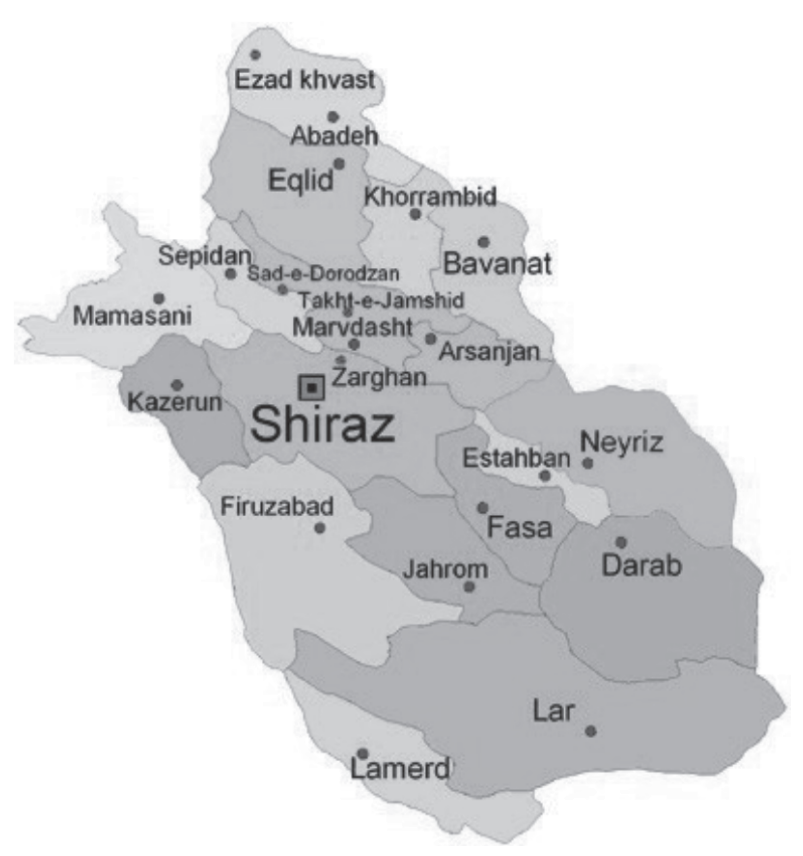

Figure 4 - Fars healthcare supply network 


\begin{tabular}{|c|c|c|c|c|c|c|c|c|c|c|c|c|c|c|c|c|c|c|c|c|c|c|c|c|c|c|c|c|c|c|c|}
\hline yeustep & & & है & Lั & 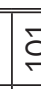 & 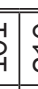 & N & लि & $\stackrel{\mathbb{N}}{\mathbf{N}}$ & $\stackrel{\mathbb{N}}{\mathbf{N}}$ & 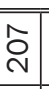 & 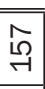 & 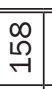 & \begin{tabular}{|l}
0 \\
$\stackrel{9}{न}$ \\
\end{tabular} & পু & 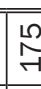 & 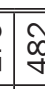 & $\overbrace{\substack{\infty \\
\infty}}^{\infty}$ & & & & & & $\underset{f}{\vec{H}}$ & $\begin{array}{l}\stackrel{m}{f} \\
f\end{array}$ & 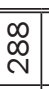 & ஓ & $\stackrel{m}{+}$ & $\begin{array}{l}0 \\
0 \\
+ \\
\end{array}$ & & \\
\hline иełsәмגеs & त & & m & $\underset{\infty}{\infty}$ & & & ใ. & 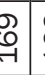 & 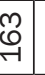 & $\stackrel{9}{\stackrel{9}{*}}$ & 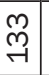 & $\begin{array}{c}m \\
\stackrel{\infty}{N} \\
\sim\end{array}$ & $\begin{array}{l}10 \\
\infty \\
\sim \\
N\end{array}$ & $\left|\begin{array}{c}\llcorner \\
\infty \\
\rightarrow\end{array}\right|$ & 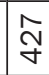 & ⿵人 & 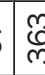 & ஃ & & & \& & 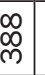 & 8 & $\stackrel{m}{\sim}$ & ले & مٌ & ลิ & \begin{tabular}{c|c}
-1 \\
0 \\
0
\end{tabular} & $\underset{\widetilde{N}}{\mathbb{N}}$ & & $\stackrel{m}{\underset{\sim}{\sim}}$ \\
\hline & & & & $m$ & 1 & & & సิ & 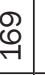 & $\vec{\forall}$ & $\vec{m}$ & প్ & 員 & $\mid \begin{array}{c}\hat{\infty} \\
m\end{array}$ & 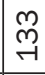 & $\stackrel{\hat{m}}{\stackrel{N}{N}}$ & 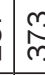 & वे & $\hat{v}^{0}$ & $\begin{array}{c}0 \\
⿱ 乛 龰\end{array}$ & 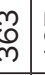 & $\begin{array}{c}\hat{6} \\
\underline{G}\end{array}$ & 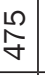 & $\stackrel{m}{\vec{\Omega}}$ & ৪ & 官 & 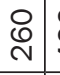 & \begin{tabular}{l}
0 \\
\multirow{2}{*}{} \\
$\forall$
\end{tabular} & 0 & & $\stackrel{m}{q}$ \\
\hline & 究 & & ด & $m$ & & & . & $\begin{array}{l}\text { : } \\
\text { en }\end{array}$ & $\underset{\sim}{\infty}$ & ֶֻ. & 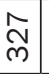 & 곳 & $\stackrel{\Delta}{N}$ & $\stackrel{\sim}{\infty}$ & 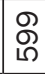 & $\bar{\curvearrowright}$ & 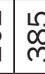 & $\left\{\begin{array}{l}a \\
\vdots \\
c\end{array}\right.$ & 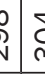 & 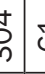 & 6 & ָे & 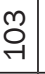 & $\stackrel{\infty}{\infty}$ & $\underset{\forall}{\forall}$ & 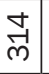 & $\stackrel{\mathscr{S}}{\stackrel{一}{2}}$ & $0\}$ & $\begin{array}{l}\underset{\mathcal{N}}{\sim} \\
\stackrel{+}{2}\end{array}$ & -1. & $\stackrel{m}{q}$ \\
\hline & & & $\vec{్}$ & 늘 & in & & W & $\begin{array}{l}\text { D. } \\
\text { me }\end{array}$ & 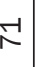 & 。్ల & 总 & 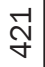 & $\begin{array}{l}\infty \\
\stackrel{y}{q}\end{array}$ & 离 & $\stackrel{N}{У}$ & 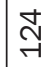 & $\stackrel{\checkmark}{\forall}$ & $\lesssim$ & v & 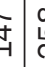 & 蜜 & $\stackrel{\infty}{\infty}$ & 㤐 & & $\begin{array}{l}\infty \\
\vec{m}\end{array}$ & $\begin{array}{c}\infty \\
\vec{m}\end{array}$ & 0 & & $\stackrel{\bullet}{\stackrel{\leftrightarrow}{N}}$ & & \\
\hline & 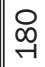 & & กิ & is & 离 & & 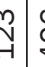 & $\begin{array}{c}\text { vo } \\
\text { v }\end{array}$ & $\begin{array}{c}\text { D) } \\
\text { Na }\end{array}$ & $\vec{\neg}$ & 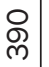 & 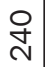 & $\begin{array}{l}\infty \\
\infty \\
\sim\end{array}$ & 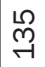 & ڤึ) & $\tilde{N}$ & 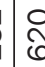 & $\begin{array}{l}\alpha \\
c\end{array}$ & 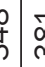 & \begin{tabular}{c|c}
0 \\
0 \\
$n$ \\
$n$
\end{tabular} & $\begin{array}{c}0 \\
\infty \\
N \\
N\end{array}$ & চ্ & స్ & $\begin{array}{l}+ \\
\text { S }\end{array}$ & 尺్ల్ల & 0 & $\begin{array}{l}\infty \\
\bar{m}\end{array}$ & $\underset{m}{\vec{m}}$ & 占 & Lإ & $\begin{array}{l}\infty \\
\infty \\
\sim \\
\sim\end{array}$ \\
\hline & & & $\stackrel{m}{\underset{\forall}{*}}$ & $\stackrel{m}{n}$ & $\underset{\sim}{\infty}$ & & $\stackrel{f}{s}$ & D & ป̊) & స్ & 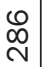 & 艿 & ⿵人丶 & $\begin{array}{l}\infty \\
o \\
o \\
q\end{array}$ & 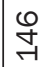 & $\stackrel{\infty}{m}$ & $\begin{array}{l}\infty \\
\infty \\
\alpha\end{array}$ & ले & 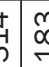 & 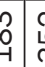 & స్ & $\begin{array}{l}\infty \\
\stackrel{d}{r}\end{array}$ & $\begin{array}{l}\infty \\
-1 \\
\end{array}$ & ك. & 0 & 吕 & $\begin{array}{c}\infty \\
m\end{array}$ & $\underset{\forall}{\vec{y}}$ & ৪ & ले & $\stackrel{m}{f}$ \\
\hline & & & 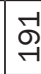 & $\begin{array}{l}\infty \\
0\end{array}$ & $\stackrel{\text { İ }}{7}$ & & $\begin{array}{l}b_{2} \\
0 \\
0\end{array}$ & תึ & $\underset{\sim}{\mathbb{N}}$ & 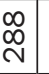 & $\underset{\mathfrak{্}}{\mathbb{N}}$ & $\begin{array}{l}8 \\
\& \\
+\end{array}$ & \begin{tabular}{|c|} 
\\
$\dot{\varphi}$ \\
$y$
\end{tabular} & 孞 & ఫ্ & $\begin{array}{l}\infty \\
\infty \\
\sim\end{array}$ & $q_{y}^{\infty}$ & 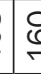 & $\overbrace{4}^{0}$ & \begin{tabular}{l|l}
$S$ & \\
\end{tabular} & 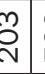 & ্ָ & 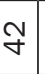 & 0 & 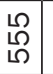 & $\begin{array}{l}\text { Oे } \\
\text { O }\end{array}$ & ১े & \begin{tabular}{l}
$\infty$ \\
\multirow{N}{*}{}
\end{tabular} & 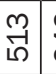 & $\begin{array}{c}m \\
\text { w }\end{array}$ & ન્ન \\
\hline дуе & 冓 & & $\stackrel{\infty}{\underset{\sim}{\sim}}$ & $\begin{array}{l}0 \\
0 \\
0 \\
0\end{array}$ & $b \mid \begin{array}{c}a \\
d\end{array}$ & & 竎 & $\begin{array}{l}y \\
y\end{array}$ & $\begin{array}{l}\substack{\infty \\
\sim} \\
\mid\end{array}$ & 号 & 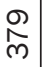 & 今) & 芦 & $\begin{array}{c}\hat{\infty} \\
\stackrel{N}{N}\end{array}$ & 㤐 & 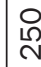 & $\stackrel{M}{q}$ & $\underbrace{}_{r}$ & $f$ & $\begin{array}{l}b_{2} \\
n\end{array}$ & 党 & $\begin{array}{l}8 \\
8 \\
6 \\
6\end{array}$ & 0 & F & 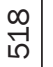 & : & 总 & 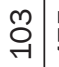 & $\begin{array}{l}\stackrel{R}{f} \\
\forall\end{array}$ & \begin{tabular}{l}
0 \\
\multirow{2}{*}{}
\end{tabular} & $\stackrel{\infty}{\sim}$ \\
\hline 140W & & & \begin{tabular}{|c|c}
$\infty$ \\
L
\end{tabular} & 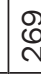 & $\bar{c}$ & & $\begin{array}{l}0 \\
0 \\
o\end{array}$ & $\begin{array}{c}0 \\
\sigma \\
c\end{array}$ & $\begin{array}{l}0 \\
\vec{\gamma}\end{array}$ & 足 & 命 & 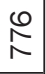 & \begin{tabular}{|c|}
$\infty$ \\
$\infty$ \\
$\wedge$ \\
\end{tabular} & $\begin{array}{l}8 \\
8 \\
0\end{array}$ & L & 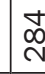 & $\mid \begin{array}{l}5 \\
s \\
n\end{array}$ & ic & t) & $\stackrel{f}{I}$ & $\begin{array}{l}f \\
\forall \\
\end{array}$ & 0 & $\begin{array}{l}0 \\
8 \\
6 \\
6\end{array}$ & হ্লি & $\begin{array}{c}\infty \\
\infty \\
\neg\end{array}$ & 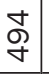 & $\begin{array}{c}\hat{\infty} \\
+ \\
+\end{array}$ & 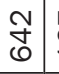 & $\begin{array}{c}\hat{G} \\
\underline{G}\end{array}$ & $\begin{array}{l}\infty \\
\infty \\
\cdots \\
m\end{array}$ & 骂 \\
\hline yәmed & $\infty$ & & $\underset{\infty}{\infty}$ & ্ָ & o & & 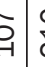 & ㄱ. & 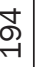 & ה & สิ & $\stackrel{m}{\stackrel{\sim}{N}}$ & 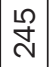 & $\stackrel{\infty}{\stackrel{2}{-}}$ & 勇 & $\stackrel{\infty}{\sim}$ & g & 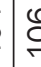 & $\begin{array}{l}b_{4}^{n} \\
\end{array}$ & 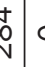 & 0 & $\vec{g}$ & 怘 & 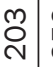 & 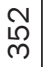 & $\begin{array}{l}\mathscr{D} \\
\infty \\
\mathbb{N}\end{array}$ & 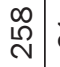 & $\overrightarrow{0}$ & 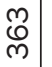 & \&) & $\mathscr{\infty}$ \\
\hline (!రె & & & $\stackrel{\infty}{\sim}$ & ڤิ & $N$ & $=\xi$ & $\begin{array}{l}0 \\
0 \\
0\end{array}$ & مِ & $\stackrel{0}{\circ}$ & 곤 & $\begin{array}{l}\hat{0} \\
\tilde{m}\end{array}$ & $\begin{array}{l}\mathscr{Q} \\
\underset{\sim}{*}\end{array}$ & I & @ & $\stackrel{\stackrel{\Omega}{\Omega}}{\mathrm{N}}$ & م & 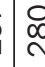 & $\begin{array}{l}\hat{A} \\
\end{array}$ & $\hat{v}$ & $b$ & $\begin{array}{c}\infty \\
\sim \\
\sim \\
\sim\end{array}$ & 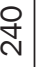 & $\begin{array}{c}0 \\
\stackrel{0}{1} \\
m\end{array}$ & $\stackrel{\mathscr{S}}{\mathrm{N}}$ & $\begin{array}{c}M \\
-\infty \\
-1\end{array}$ & $\overrightarrow{\substack{0 \\
m}}$ & $\underset{\forall}{*}$ & $\begin{array}{l}\text { ¿े } \\
\text { la }\end{array}$ & $\stackrel{\infty}{\circ}$ & $\stackrel{m}{\sim}$ & 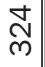 \\
\hline ueque & छ & ণ্ & & 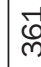 & $\begin{array}{l}\xi \\
\vdots\end{array}$ & & $\mathrm{N}$ & 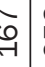 & ֻِ & $\begin{array}{c}\infty \\
\stackrel{m}{m}\end{array}$ & ले & 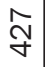 & $\hat{\infty}$ & : & $\begin{array}{l}0 \\
\vdots \\
1\end{array}$ & $\underset{\sim}{\infty}$ & $\frac{\partial}{\sigma}$ & $c$ & $b$ & $\hat{v}$ & 足 & 离 & f & 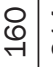 & $\stackrel{\vec{m}}{\vec{m}}$ & 京 & $\stackrel{\sim}{N}$ & $\begin{array}{l}\infty \\
\stackrel{\sim}{N}\end{array}$ & $\begin{array}{l}0 \\
\stackrel{N}{m}\end{array}$ & & $\stackrel{\infty}{\stackrel{\infty}{N}}$ \\
\hline & ธุ & & $\begin{array}{l}\infty \\
\stackrel{\infty}{q}\end{array}$ & $\begin{array}{l}\infty \\
\widetilde{\vartheta}\end{array}$ & 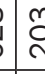 & & 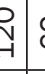 & $\widehat{c}$ & ָै & & 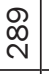 & 氖 & 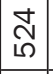 & $\begin{array}{c}0 \\
\stackrel{\leftrightarrow}{\mathrm{N}} \\
\end{array}$ & $\underset{⿱}{\mathbb{N}}$ & $\overrightarrow{0}$ & 0 & $\underset{\partial}{\sigma}$ & $\begin{array}{l}\text { va } \\
\text { tha }\end{array}$ & $\begin{array}{l}D \\
\text { De }\end{array}$ & 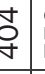 & 疍 & 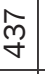 & $\begin{array}{l}\infty \\
0 \\
0 \\
\end{array}$ & $\begin{array}{l}m \\
\stackrel{\infty}{N}\end{array}$ & $\begin{array}{l}\stackrel{2}{ } \\
0 \\
\end{array}$ & $\begin{array}{l}\vec{\forall} \\
\end{array}$ & $\begin{array}{l}\stackrel{L}{\infty} \\
\stackrel{m}{m}\end{array}$ & $\begin{array}{c}m \\
\stackrel{m}{m}\end{array}$ & $\begin{array}{l}n \\
0 \\
\text { e }\end{array}$ & $\begin{array}{l}\mathcal{N} \\
\stackrel{\infty}{\sigma}\end{array}$ \\
\hline & 이 & & $\underset{\sim}{\hat{\sigma}}$ & ণ্ & $\stackrel{5}{7}$ & & $\begin{array}{l}0 \\
0 \\
-1 \\
-1\end{array}$ & $\stackrel{0}{6}$ & 8) & $\begin{array}{c}0 \\
\text { ลे }\end{array}$ & $\stackrel{-\vec{~}}{\sim}$ & $\widehat{\stackrel{\omega}{N}}$ & 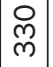 & $\left|\begin{array}{c}\mathfrak{G} \\
\stackrel{-}{-}\end{array}\right|$ & $\underset{\sim}{\stackrel{\sim}{~}}$ & 0 & $\bar{c}$ & $a_{\alpha}^{o}$ & \begin{tabular}{c|c}
0 \\
\hdashline \\
\end{tabular} & $\stackrel{5}{5}$ & $\stackrel{\infty}{\underset{\sim}{*}}$ & 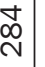 & \& & $\begin{array}{c}\infty \\
\infty \\
\sim\end{array}$ & $\begin{array}{l}\infty \\
\vec{m}\end{array}$ & 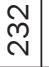 & 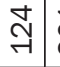 & م્ & $\widehat{\tilde{N}}$ & & $\underset{\sim}{\stackrel{2}{\sigma}}$ \\
\hline & & & 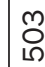 & ন & 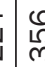 & & $\begin{array}{l}\delta_{y} \\
y\end{array}$ & 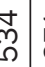 & 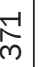 & $\begin{array}{l}0 \\
0 \\
0\end{array}$ & $\begin{array}{l}0 \\
0 \\
1\end{array}$ & ल) & 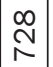 & \begin{tabular}{|l|l} 
\\
: \\
1
\end{tabular} & 0 & $\underset{\sim}{\mathbb{N}}$ & 卞 & $\mathbb{S}_{i}^{\mathbb{S}}$ & \begin{tabular}{c|c|c} 
\\
\end{tabular} & S. & 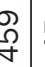 & เ & 굥 & ఫ్ & \begin{tabular}{l}
0 \\
\multirow{H}{*}{}
\end{tabular} & 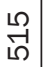 & $\begin{array}{l}\mathcal{Y} \\
\mathcal{7}\end{array}$ & ஜ্.ి & $\stackrel{m}{\vec{G}}$ & $\underset{\sim}{\widetilde{\gamma}}$ & প্ণ \\
\hline & $\sqrt{-1}$ & & 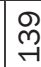 & $\stackrel{\infty}{\stackrel{\infty}{f}}$ & $: \begin{array}{l}0 \\
\delta\end{array}$ & & 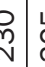 & స్ల̂) & $\begin{array}{l}0 \\
\text { a } \\
\end{array}$ & $\begin{array}{l}\stackrel{2}{~} \\
\text { | }\end{array}$ & న్ & $\hat{\tilde{\omega}}$ & \begin{tabular}{|l|} 
\\
\\
\end{tabular} & 0 & 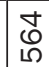 & ్ֶ & 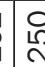 & 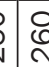 & 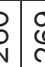 & $\begin{array}{lll}0 \\
0\end{array}$ & $\begin{array}{c}\infty \\
\frac{1}{n}\end{array}$ & 88 & 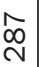 & D్ & $\begin{array}{l}\infty \\
0 \\
0\end{array}$ & 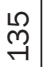 & 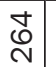 & 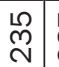 & $\widehat{\substack{\infty \\
m}}$ & 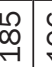 & $\begin{array}{l}\mathscr{O} \\
\stackrel{9}{1}\end{array}$ \\
\hline & $\bar{\lambda}$ & & $\stackrel{\stackrel{\sim}{\sim}}{\sim}$ & 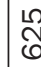 & 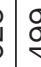 & & d & 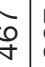 & $\begin{array}{l}\hat{0} \\
0 \\
m\end{array}$ & $\begin{array}{c}\mathfrak{N} \\
\stackrel{y}{*}\end{array}$ & $\begin{array}{l}0 \\
\vdots \\
\square\end{array}$ & $\begin{array}{c}\stackrel{0}{\rightarrow} \\
\vec{r}\end{array}$ & 0 & \begin{tabular}{|l|} 
o \\
|
\end{tabular} & $\underset{N}{\infty}$ & 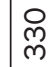 & $\mid \begin{array}{l}7 \\
\text { is }\end{array}$ & $\hat{a}$ & 5 & \begin{tabular}{l}
$y$ \\
\multirow{y}{y}{} \\
\end{tabular} & 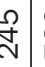 & م & 志 & $\begin{array}{l}\hat{o} \\
\dot{q}\end{array}$ & 各 & $\begin{array}{c}\infty \\
\stackrel{\infty}{\sim} \\
\stackrel{N}{n}\end{array}$ & $\begin{array}{l}\infty \\
\tilde{\sigma} \\
\checkmark\end{array}$ & $\underset{\sim}{\mathbb{N}}$ & 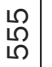 & 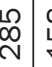 & $\begin{array}{l}\text { 足 } \\
\stackrel{\sim}{\sim}\end{array}$ \\
\hline$p ! \mid b \exists$ & 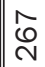 & $\underset{\text { Y }}{\stackrel{y}{y}}$ & $\stackrel{\infty}{N}$ & ᄂి & 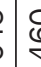 & & 忽 & $\begin{array}{l}\sigma^{\prime} \\
g\end{array}$ & $\begin{array}{l}0 \\
0 \\
0\end{array}$ & $\stackrel{\stackrel{\sim}{\sim}}{\underset{f}{2}}$ & 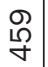 & 0 & 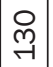 & \begin{tabular}{|l}
$\hat{0}$ \\
en
\end{tabular} & 六 & $\hat{\mathfrak{o}}$ & is & $\hat{\jmath}$ & $\begin{array}{c}j \\
y\end{array}$ & 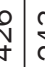 & $\begin{array}{c}m \\
\stackrel{m}{*}\end{array}$ & $\begin{array}{l}0 \\
2 \\
1\end{array}$ & & $\begin{array}{l}8 \\
\vdots \\
+\end{array}$ & 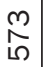 & 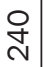 & $\underset{\Im}{ন}$ & ㄱ. & প্ & $\begin{array}{c}\infty \\
\text { d } \\
\text {, }\end{array}$ & 令 \\
\hline $\mathrm{zl}$ & \% & & $\overrightarrow{\widetilde{N}}$ & §ิ & $\oint_{\sigma}$ & & $\begin{array}{l}\text { f } \\
-1\end{array}$ & S. & $\begin{array}{l}\infty \\
\infty \\
m \\
m\end{array}$ & 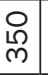 & 0 & $\begin{array}{l}\stackrel{8}{8} \\
\stackrel{f}{q}\end{array}$ & \begin{tabular}{|l|} 
\\
0 \\
+
\end{tabular} & 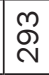 & $\begin{array}{l}0 \\
1 \\
1 \\
\end{array}$ & $\overrightarrow{\stackrel{N}{N}}$ & $\begin{array}{l}\infty \\
\infty\end{array}$ & ल & $\begin{array}{l}v \\
b \\
a\end{array}$ & 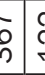 & & જூ & 胥 & $\underset{\underset{\sim}{N}}{\mathbb{N}}$ & $\begin{array}{l}\stackrel{0}{\infty} \\
\stackrel{\infty}{N}\end{array}$ & ৪্লি & $\begin{array}{l}0 \\
b \\
m \\
m\end{array}$ & 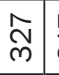 & $\vec{m}$ & 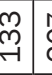 & \\
\hline & vo & 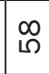 & $\stackrel{\widehat{్}}{\mathrm{~N}}$ & is & \begin{tabular}{|l|l} 
\\
\end{tabular} & & $\begin{array}{l}x_{0}^{0} \\
\text { N }\end{array}$ & $\begin{array}{ll}m \\
\infty \\
m\end{array}$ & 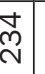 & 0 & 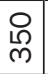 & $\stackrel{\stackrel{\llcorner}{\sim}}{\underset{\sim}{2}}$ & \begin{tabular}{|c|}
\multirow{m}{\forall}{} \\
\end{tabular} & 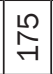 & 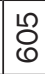 & $\stackrel{0}{\mathrm{~N}}$ & $\lesssim$ & $\frac{\alpha}{\Omega}$ & \begin{tabular}{l|l}
0 \\
0 \\
\end{tabular} & $S^{S}$ & $\underset{N}{N}$ & 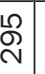 & 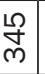 & $\begin{array}{l}\infty \\
\substack{\infty \\
N}\end{array}$ & 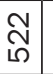 & $\vec{\exists}$ & $\begin{array}{l}\text { ¿ి } \\
0\end{array}$ & 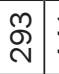 & $\underset{f}{J}$ & 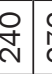 & \\
\hline peqe & nু & 0 & $\underset{\sim}{\sim}$ & 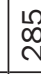 & $y$ & & N & $\begin{array}{c}\infty \\
\vec{m} \\
\end{array}$ & 0 & 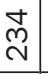 & 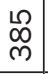 & $\begin{array}{l}0 \\
0 \\
m\end{array}$ & $\begin{array}{l}\hat{0} \\
\tilde{m}\end{array}$ & $\begin{array}{l}m \\
\stackrel{9}{न} \\
\end{array}$ & î & 요 & $\mathrm{f}_{\mathrm{m}}$ & 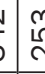 & 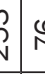 & 2 & ఫ્ન & $\begin{array}{l}0 \\
\forall \\
\forall\end{array}$ & $\begin{array}{l}0 \\
\stackrel{\infty}{N} \\
\sim\end{array}$ & $\underset{N}{\mathbb{N}}$ & $\stackrel{\llcorner}{\sim}$ & $\begin{array}{l}m \\
\stackrel{\infty}{N} \\
N\end{array}$ & ה & $\stackrel{\infty}{N}$ & $\underset{G}{\mathscr{G}}$ & $\begin{array}{l}\tilde{\theta} \\
\end{array}$ & 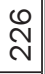 \\
\hline & $\stackrel{\stackrel{\sim}{N}}{N}$ & $m$ & 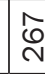 & হి & $\frac{a}{2}$ & & ภี & 0 & $\begin{array}{l}\infty \\
\vec{m}\end{array}$ & 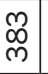 & $\begin{array}{l}\stackrel{\mathscr{g}}{二} \\
\stackrel{4}{2}\end{array}$ & হু & \begin{tabular}{|l|} 
\\
$\dot{y}$ \\
\end{tabular} & $\begin{array}{l}\stackrel{\sim}{N} \\
\tilde{m}\end{array}$ & 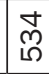 & $\hat{\mathscr{Q}}$ & 8 & $\hat{c}$ & 5 & 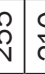 & ज. & 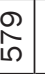 & $\underset{\forall}{\stackrel{y}{f}}$ & 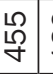 & $\begin{array}{l}8 \\
\infty \\
\rightarrow\end{array}$ & $\begin{array}{l}\underset{N}{⿰} \\
\underset{\checkmark}{ }\end{array}$ & $\begin{array}{l}\mathscr{D} \\
m\end{array}$ & $\begin{array}{l}\text { ठ } \\
\text { D }\end{array}$ & $\stackrel{\mathbb{N}}{\mathrm{N}}$ & $\begin{array}{l}8 \\
\stackrel{-}{-1} \\
\end{array}$ & $\stackrel{m}{m}$ \\
\hline & $\stackrel{\text { }}{\rightarrow}$ & N & $\underset{-1}{0}$ & 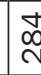 & $\stackrel{c}{\alpha}$ & & o & o. & $\underset{\sim}{*}$ & $\begin{array}{c}\infty \\
\infty \\
\sim \\
\sim\end{array}$ & $\underset{+}{\stackrel{q}{*}}$ & 命 & $\begin{array}{l}\stackrel{N}{m} \\
m\end{array}$ & $\underset{\sim}{\stackrel{D}{N}}$ & 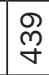 & $\underset{G}{G}$ & $\stackrel{\overbrace{}}{7}$ & ก & $v$ & on & $\overrightarrow{0}$ & $\begin{array}{l} \\
\infty \\
\forall\end{array}$ & $\vec{m}$ & $\begin{array}{l}8 \\
0 \\
m\end{array}$ & 守 & $\underset{\sim}{\stackrel{m}{\sim}}$ & ১े & $\begin{array}{l}0 \\
0 \\
-1\end{array}$ & 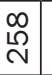 & $\begin{array}{l}0 \\
0\end{array}$ & 고 \\
\hline & & m & 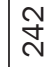 & 옹 & 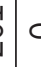 & & $\begin{array}{l}n \\
0\end{array}$ & $\begin{array}{c}\infty \\
-\infty \\
\end{array}$ & $\begin{array}{l}0 \\
0 \\
\ddots\end{array}$ & 点 & 号 & $\begin{array}{l}\& \\
q\end{array}$ & $\mid \begin{array}{l}\mathscr{g} \\
\stackrel{9}{2}\end{array}$ & 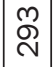 & 怘 & $\stackrel{\text { I }}{\mathrm{f}}$ & co & 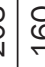 & $\hat{T}$ & $=\begin{array}{l}8 \\
0\end{array}$ & $\widehat{\sigma}$ & 苂 & $\begin{array}{l}\text { D } \\
\text { M }\end{array}$ & $\underset{\mathcal{F}}{\mathcal{F}}$ & 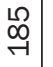 & 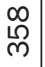 & 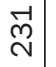 & $\begin{array}{l}\infty \\
\stackrel{N}{m}\end{array}$ & 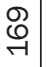 & | & 웜 \\
\hline & c & & $\stackrel{\vartheta}{\forall}$ & 0 & & & 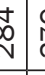 & $\begin{array}{l}g \\
m\end{array}$ & 禺 & $\begin{array}{l}9 \\
\stackrel{9}{10}\end{array}$ & ๙ু & 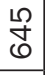 & \begin{tabular}{|l}
$\stackrel{1}{0}$ \\
$\tilde{N}$ \\
\end{tabular} & \begin{tabular}{l}
$\infty$ \\
\multirow{f}{f}{} \\
\end{tabular} & $\stackrel{\mathbb{N}}{\mathbb{N}}$ & ন্ & $\left(\begin{array}{l}\infty \\
\vdots\end{array}\right.$ & d) & 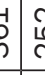 & 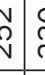 & ल्ల్ & 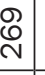 & $\begin{array}{l}1 \\
0 \\
0 \\
1\end{array}$ & $\begin{array}{l}\infty \\
8 \\
\bullet\end{array}$ & $\stackrel{m}{N}$ & 宫 & $\begin{array}{l}\stackrel{\bullet}{1} \\
\stackrel{m}{m}\end{array}$ & $\begin{array}{l}m \\
1 \\
i\end{array}$ & $\stackrel{m}{\exists}$ & $\begin{array}{l}\infty \\
\stackrel{\infty}{\sim} \\
\end{array}$ & 옴 \\
\hline & প্ল & & 0 & Э & $i c_{c}$ & & $\begin{array}{ll}8 \\
\end{array}$ & 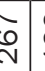 & $\begin{array}{c}\vec{N} \\
\vec{\sim} \\
\end{array}$ & & $\overrightarrow{\stackrel{m}{N}}$ & $\stackrel{\infty}{\underset{N}{N}}$ & $\begin{array}{l}\stackrel{\sim}{N} \\
\sim\end{array}$ & \begin{tabular}{|l|} 
\\
$m$ \\
$\sim$
\end{tabular} & $\begin{array}{l}0 \\
0 \\
0\end{array}$ & $\stackrel{\circ}{\circ}$ & $\begin{array}{l}\infty \\
q\end{array}$ & 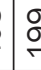 & 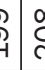 & 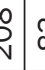 & 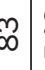 & 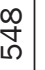 & $\stackrel{\infty}{\underset{\sim}{\sim}}$ & S̆ & $\stackrel{m}{\vec{y}}$ & 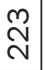 & $\hat{\exists}$ & 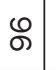 & ल) & & 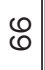 \\
\hline & छ & & 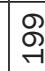 & $\vec{\varphi}$ & $\vec{c}$ & 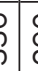 & $\begin{array}{ll}S_{2} \\
\text { N }\end{array}$ & $\begin{array}{ll} \\
m \\
m \\
m\end{array}$ & $\begin{array}{c}\infty \\
\infty \\
\rightarrow \\
\rightarrow\end{array}$ & $\begin{array}{l}\infty \\
\stackrel{\infty}{\infty}\end{array}$ & 孞 & $\underset{\mathcal{N}}{\mathfrak{N}}$ & 守 & $\begin{array}{l}m \\
\stackrel{m}{N}\end{array}$ & 告 & g & $\frac{9}{7}$ & ¿ & 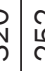 & 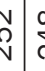 & 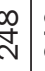 & 守 & 㝎 & ণ & ৪ & $\stackrel{R}{\wedge}$ & $\stackrel{\text { L }}{0}$ & $\stackrel{\circ}{\stackrel{\sim}{\sim}}$ & $\begin{array}{l}\infty \\
\vec{\gamma}\end{array}$ & ลे| & ผै \\
\hline \multirow[t]{2}{*}{ zex!us } & 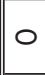 & 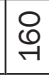 & প্ল & $\stackrel{\infty}{\stackrel{\infty}{m}}$ & $\frac{8}{\sigma}$ & $\begin{array}{l}\mathrm{N} \\
\mathrm{T} \\
\mathrm{T}\end{array}$ & $\begin{array}{l}D_{n} \\
-1 \\
\end{array}$ & N̦ & ळ. & 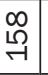 & $\vec{\sim}$ & 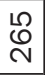 & 蚉 & 迆 & \begin{tabular}{l}
\multirow{2}{*}{} \\
$\mathscr{q}$
\end{tabular} & 8 & ڤ̊ & 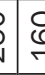 & 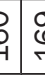 & o & 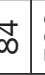 & $\begin{array}{l}8 \\
8 \\
0\end{array}$ & \begin{tabular}{|l|} 
\\
$\infty$ \\
-1 \\
-1
\end{tabular} & 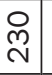 & $\begin{array}{l}\stackrel{g}{\Omega} \\
m\end{array}$ & $\begin{array}{c}\infty \\
\infty \\
\neg \\
\neg \\
\end{array}$ & $\begin{array}{l}0 \\
0 \\
-1\end{array}$ & $\begin{array}{l}\stackrel{\llcorner}{m} \\
\rightarrow \\
\rightarrow\end{array}$ & 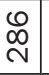 & $\infty$ & 9 \\
\hline & & & & & & & $\begin{array}{c}\frac{1}{10} \\
1\end{array}$ & 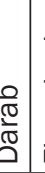 & 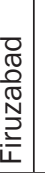 & & & & \begin{tabular}{|l|}
$\frac{0}{0}$ \\
$\frac{\pi}{\alpha}$ \\
$\frac{8}{\alpha}$
\end{tabular} & & 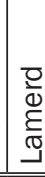 & $\begin{array}{l}1 \\
\text { d. } \\
\text { du } \\
\end{array}$ & $\begin{array}{ll}\frac{\pi}{\pi} \\
\frac{\pi}{\pi} \\
: \frac{\pi}{3} \\
:\end{array}$ & & & & & & & & $\begin{array}{l}\frac{1}{\infty} \\
\mathbb{0} \\
0 \\
\mathbb{0}\end{array}$ & 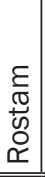 & 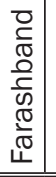 & 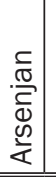 & & & \\
\hline
\end{tabular}




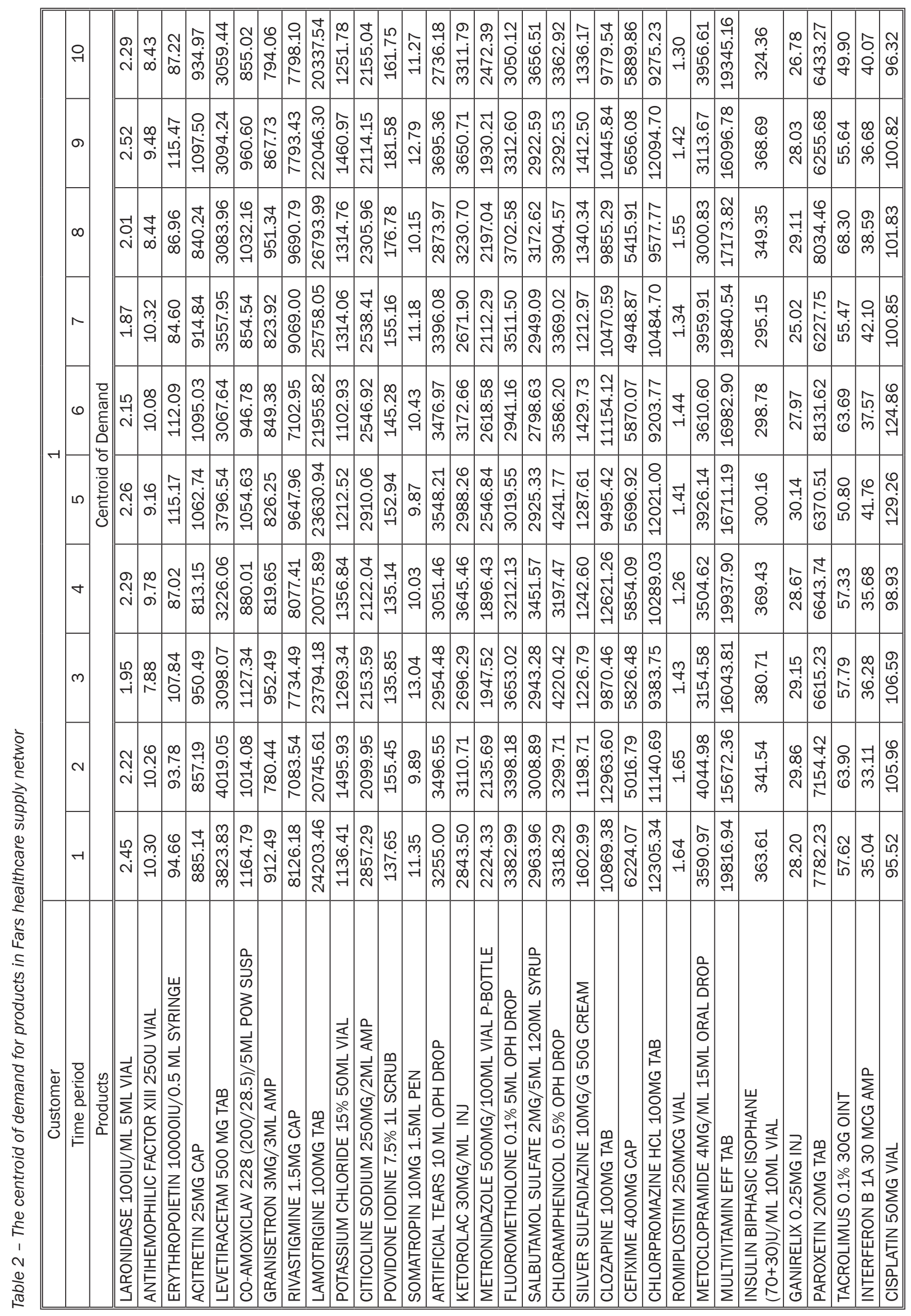


Table 3 - Products classification

\begin{tabular}{||c|l|c|l|c|l||}
\hline \hline Index & \multicolumn{1}{|c|}{ Product class } & Index & \multicolumn{1}{c|}{ Product class } & Index & \multicolumn{1}{|c||}{ Product class } \\
\hline \hline 1 & Analgesic drugs & 18 & Blood products & 34 & Anesthetics \\
\hline 2 & Anthelmintics & 19 & Bone modulating & 35 & Muscle relaxants \\
\hline 3 & Antibacterials & 20 & Anti-asthma & 36 & Neuromuscular blockers \\
\hline 4 & Antidepressants & 21 & Cardiovascular drugs & 37 & Parasympathomimetics \\
\hline 5 & Anti-diabetics & 22 & Antidote and antagonists & 38 & Pesticides and repellents \\
\hline 6 & Antiepileptics & 23 & Contrast media & 39 & Prostaglandins \\
\hline 7 & Antifungals & 24 & Corticosteroids & 40 & Sex hormones \\
\hline 8 & Antigout drugs & 25 & Cough suppressants & 41 & Suspending agents \\
\hline 9 & Anti-histamines & 26 & Dermatological & 42 & Stimulants and anorectics \\
\hline 10 & Antimalarials & 27 & Disinfectants & 43 & Thyroid drugs \\
\hline 11 & Antimigraine drugs & 28 & Dopaminergics & 44 & Vaccines \\
\hline 12 & Antimuscarinics & 29 & Electrolytes & 45 & Herbal drugs \\
\hline 13 & Antineoplastics & 30 & Gastrointestinal drugs & 46 & Others \\
\hline 15 & Antiprotozoals & 31 & Anesthetics & 47 & Nutritional agents \\
\hline 16 & Antivirals & 32 & Hypothalamic and pituitary & & and vitamins \\
\hline 17 & Sedatives \& hypnotics & 33 & Immunosuppressants & & \\
\hline
\end{tabular}

developed by Deb et al. based on the genetic algorithm [53]. Like other evolutionary algorithms, in the first step NSGA-II generates random solutions with the population of $\mu$. In addition, each solution is evaluated by fitness functions, and, based on this evaluation, Pareto fronts are created by non-domination sorting. In the next step, each solution receives a rank equal to the level of the front that it belongs to. Then the crowding distance between the solutions on each front is measured. The selection procedure is the binary tournament method. The winner is the solution with the higher rank, and if the ranks are equal, the winner is the one with the higher crowding distance. The rest of the NSGA-II procedure is exactly the same as the genetic algorithm [54]. Moore and Chapman were the first to present MOPSO [55]. The procedure of MOPSO is similar to PSO. The only difference is that since the problem is multi-objective, instead of determining global best solution (G-best), the Pareto front would be determined. So, an archive including all of non-dominated solutions found in each iteration are stored. The steps of MOPSO are:

1) Initialize random solutions with the population of $\mu$ and the archive of non-dominated solutions.
2) For each solution: a) Select the G-best from the archive; b) Update velocity; c) Update position

3) Update the archive of non-dominated solutions

4) Repeat [55].

In the presented case study, to measure TRCE, a vector with $B=1,000,000$ array for each probabilistic and fuzzy numbers based on their probability density function or fuzzy membership function is generated by MATLAB 2012a. Then the histogram and Kolmogorov-Smirnov test is calculated to estimate the possibility distribution function of TRCE.

\subsection{Results}

The presented problem is solved by NSGA-II, MOPSO, and M-NRGA. The input parameters of these algorithms are given in Table 4. Four common measures are used to compare the algorithms. The most important index is the quality of solutions. This index cannot be measured for a Pareto front individually and must be calculated comparing to another Pareto front. Assume $P_{i}$ is the Pareto front resulted by algorithm $i$, and $P_{j}$ is the Pareto front resulted by algorithm $j$, then the quality index for algorithm $i$ and $j\left(Q\left(P_{i}, P_{j}\right)\right)$ can be calculated by Equations 29 and 30.

Table 4 - The input parameters of NSGA-II, MOPSO and M-NRGA

\begin{tabular}{|c|c|c|c|c|c|c|}
\hline \multirow{2}{*}{ NSGA-II } & Number of population & Maximum iteration & \multicolumn{3}{|c|}{ Crossover rate } & Mutation\% \\
\hline & 100 & 100 & \multicolumn{3}{|c|}{0.65} & 5 \\
\hline \multirow{2}{*}{ MOPSO } & Number of population & Maximum iteration & $C_{1}$ & $C_{2}$ & $\omega$ & Mutation\% \\
\hline & 100 & 100 & 1.9 & 2.1 & 0.8 & 5 \\
\hline \multirow{2}{*}{ M-NRGA } & Number of population & Maximum iteration & $P$ & & $P_{t}$ & Mutation\% \\
\hline & 100 & 100 & \multicolumn{3}{|c|}{ Adjustable } & 5 \\
\hline
\end{tabular}


$C\left(P_{i}, P_{j}\right)=\frac{\text { Number of solutions in } P_{j} \text { dominated by solutions in } P_{i}}{\text { Number of solutions in } P_{j}}$

$Q\left(P_{i}, P_{j}\right)=\frac{C\left(P_{i}, P_{j}\right)}{C\left(P_{i}, P_{j}\right)+C\left(P_{j}, t\right.}$

Considering Equations 29 and 30 , it is clear that $Q\left(P_{i}, P_{j}\right)+Q\left(P_{j}, P_{i}\right)=1$. For the quality index, if $Q\left(P_{i}, P_{j}\right)>Q\left(P_{j}, P_{i}\right)$, then the Pareto front resulted by algorithm $i$ is better than the Pareto front resulted by algorithm $j$ [56].

The next index for evaluating the performance of a multi-objective algorithm is the diversity of the solutions in the Pareto front $\left(D\left(P_{i}\right)\right)$. The higher value of this index shows the better performance of the multi-objective algorithm. The diversity of solutions in a Pareto front is calculated as presented in Equation 31.

$$
D\left(P_{i}\right)=\sum_{z=1}^{j} \max _{k, l}\left\{\left|Z_{j}\left(X_{k}\right)-Z_{j}\left(X_{l}\right)\right|\right\}
$$

where $Z_{j}$ is the objective function $j$ and $X_{k}$ is the solution in Pareto front $P_{i}$ [56]. Two other indexes are CPU time and the number of solutions in the Pareto front (NSPF). The higher number of solutions in the Pareto front is more preferable because it can give the decision makers more options. We solve the presented case study 100 times. For the presented problem, Table 5 shows the quality index for presented algorithms, and other indexes are presented in Table 6.
As presented in Table 5, the average of $Q$ (MOPSO,NSGA-II) is higher than $Q$ (NSGA-II,MOPSO), so, based on the quality index, the first assumption is that MOPSO performs better than NSGA-II. Similarly, based on the quality index, we can assume that M-NRGA performs better than both MOPSO and NSGA-II. Table 6 shows that, on average, NSGA-II has better performance in CPU time. In addition, the average number of solutions in the Pareto front is higher in M-NRGA. The average diversity of the solutions in the Pareto front is higher in M-NRGA. It should be mentioned, since in the proposed M-NRGA $P_{e}$ present of solutions are selected based on elitism from the elitist solutions in the first front, by adjusting $P_{e}$ the number of solutions in the Pareto front can be adjusted to be at least equal to a fix number. In this paper, we consider 30 as the minimum number of solutions in the Pareto front.

To ensure that the presented algorithm can solve the network design problem efficiently and in reasonable time, statistical tests are implemented [57]. The confidence level of $99 \%$ is considered for all of the tests. The first test is if NSGA-II performs better than the proposed M-NRGA in each index, and the second one is if MOPSO performs better than M-NRGA in each index at the confidence level of $99 \%$. As presented in Table 7 , both MOPSO and NSGA-II have a better CPU time comparing to M-NRGA. However, in terms of the

Table 5 - Quality index for presented algorithms

\begin{tabular}{||c|c|c|c|c|c|c|c||}
\hline \multirow{2}{*}{ Sample size } & \multirow{2}{*}{$Q\left(P_{i}, P_{j}\right)$} & \multicolumn{3}{|c|}{ Mean } & \multicolumn{3}{|c||}{ Standard deviation } \\
\cline { 3 - 8 } & & NSGA-II & MOPSO & M-NRGA & NSGA-II & MOPSO & M-NRGA \\
\hline \hline 100 & NSGA-II & - & 0.4877 & 0.3563 & - & 0.12 & 0.09 \\
\hline 100 & MOPSO & 0.5123 & - & 0.3649 & & - & 0.08 \\
\hline 100 & M-NRGA & 0.6437 & 0.6351 & - & 0.21 & 0.18 & - \\
\hline
\end{tabular}

Table 6 - The value of indexes for presented algorithms

\begin{tabular}{||l|c|c|c|c|c|c|c||}
\hline & \multicolumn{4}{|c|}{ Mean } & \multicolumn{3}{c||}{ Standard deviation } \\
\hline \hline Index & Sample size & NSGA-II & MOPSO & M-NRGA & NSGA-II & MOPSO & M-NRGA \\
\hline CPU Time [s] & 100 & $7,439.34$ & $8,643.21$ & $8,941.62$ & 632.71 & 501.51 & 781.42 \\
\hline NSPF & 100 & 18.42 & 16.23 & 30 & 4.32 & 3.21 & 0 \\
\hline & 100 & $5,294,031.11$ & $7,768,633.35$ & $8,345,223.32$ & $123,122.74$ & $143,287.46$ & $168,231.51$ \\
\hline
\end{tabular}

Table 7 - The statistical tests results for all hypotheses

\begin{tabular}{||c|l|c||}
\hline \multicolumn{1}{||}{$H_{0}$ (null hypothesis) } & \multicolumn{1}{|c|}{ Test problem index } & P-value \\
\hline \hline \multirow{4}{*}{ NSGA-II performs better than M-NRGA } & Quality index of the Pareto front & 0.000 \\
\cline { 2 - 3 } & CPU time [s] & 1.000 \\
\cline { 2 - 3 } & Number of solutions in the Pareto front & 0.000 \\
\cline { 2 - 3 } & Diversity of the Pareto front & 0.000 \\
\hline \multirow{4}{*}{ MOPSO performs better than M-NRGA } & Quality index of the Pareto front & 0.000 \\
\cline { 2 - 3 } & CPU time [s] & 0.342 \\
\cline { 2 - 3 } & Number of solutions in the Pareto front & 0.000 \\
\cline { 2 - 3 } & Diversity of the Pareto front & 0.000 \\
\hline
\end{tabular}




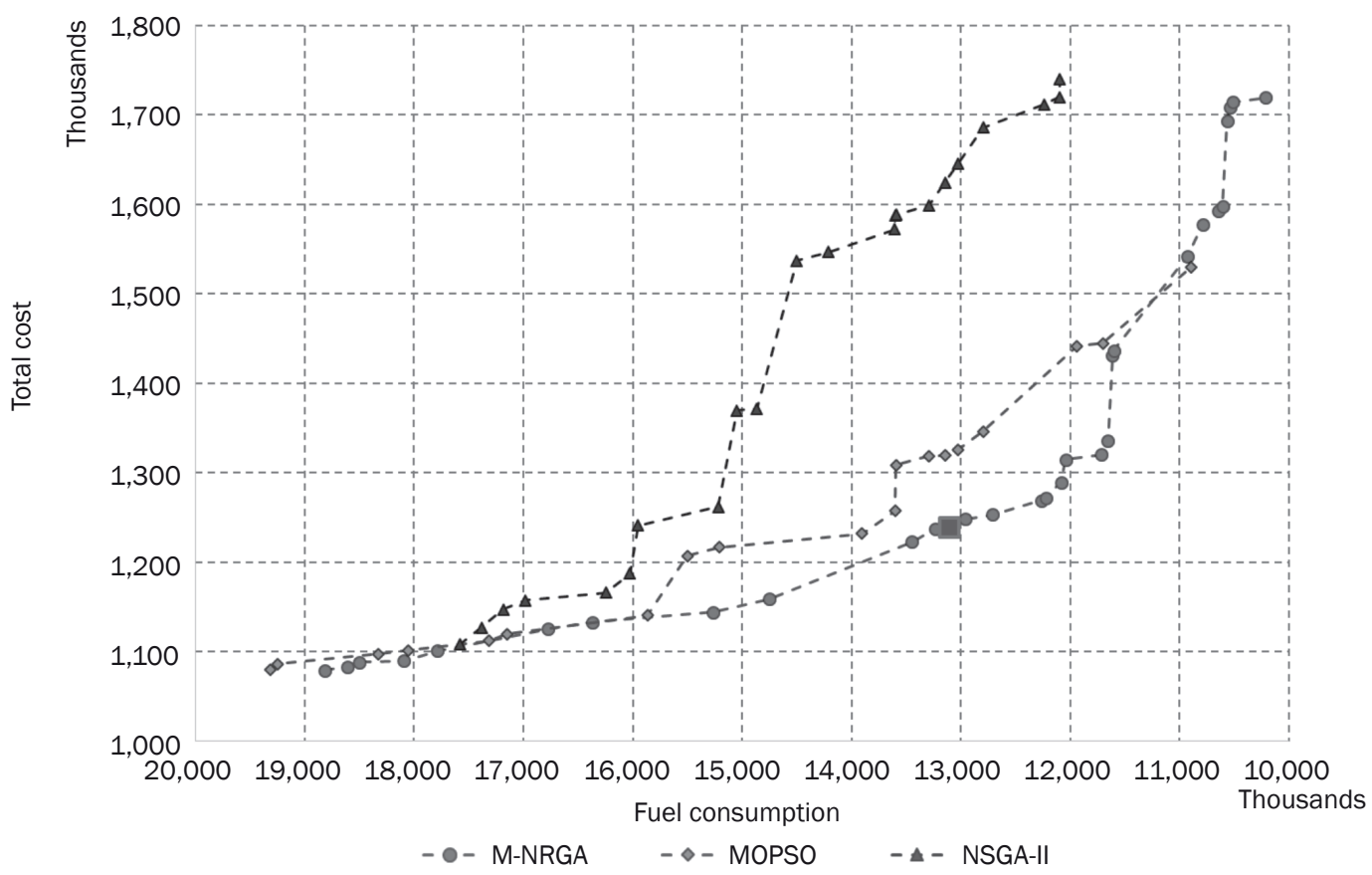

Figure 5 - The best Pareto fronts for the Fars healthcare supply network design problem, based on quality index

quality index of the Pareto front, number of solutions in the Pareto front, and Pareto front diversity, the performance of M-NRGA is better.

As mentioned before, the most important index for evaluating Pareto fronts is the quality index. The best Pareto fronts for the Fars healthcare supply network design problem, based on this index, are illustrated in Figure 5 and Table 8. As presented in Table 8, according to Equation 18, the diversity of the solutions in the Pareto front resulted from M-NRGA amounts to $9,235,474.32$, from MOPSO to $8,868,654.35$, and from NSGA-II to $6,119,401.00$.
Based on Equations 29 and 30, Q(M-NRGA,NSGA-II) $=1$ and $Q($ M-NRGA,MOPSO $)=0.966$. So, according to these indexes, M-NRGA performs better than the other two algorithms. However, in the CPU time index, NSGA-II preforms better.

To find the best solution in the Pareto front resulted from M-NRGA, as presented in the solution algorithm, PROMETHEE-II was applied. The best solution is also shown in Figure 7 . For this solution, Objective function 2 - minimizing total cost - is: $1,237,447.6 \$$, and $O b$ jective function 3 - minimizing fuel consumption - is: 13,233,837.6 liters.

Table 8 - Best Pareto front for the presented problem based on quality index

\begin{tabular}{||c|c|c|c|c|c||}
\hline Algorithm & $Z_{1}$ & $Z_{2}$ & CPU time [s] & NSPF & $D\left(P_{i}\right)$ \\
\hline \hline M-NRGA & $1,079,481.97$ & $10,217,546.41$ & $8,746.21$ & 30 & $9,235,474.32$ \\
\hline MOPSO & $1,079,562.97$ & $10,894,725$ & $8,668.34$ & 19 & $8,868,573.35$ \\
\hline NSGA-II & $1,107,998$ & $12,094,725$ & $7,365.41$ & 22 & $6,119,401.00$ \\
\hline
\end{tabular}

Table 9 - Descriptive statistics of TRCE

\begin{tabular}{|c|c|c|c|c|}
\hline & & & Statistic & Std. error \\
\hline \multirow{9}{*}{ TRCE } & \multicolumn{2}{|c|}{ Mean } & $32,007,127,597.94434$ & $8,261,135.309457544$ \\
\hline & \multirow{2}{*}{$\begin{array}{l}95 \% \text { confidence } \\
\text { Interval for mean }\end{array}$} & Lower bound & $31,990,936,055.797$ & \\
\hline & & Upper bound & $32,023,319,140.09168$ & \\
\hline & \multicolumn{2}{|c|}{ 5\% Trimmed mean } & $32,005,466,357.367813$ & \\
\hline & \multicolumn{2}{|c|}{ Median } & $31,998,456,877.6218$ & \\
\hline & \multicolumn{2}{|c|}{ Variance } & $6.8246288 E+19$ & \\
\hline & \multicolumn{2}{|c|}{ Std. deviation } & $8,261,131,178.888857$ & \\
\hline & \multicolumn{2}{|c|}{ Minimum } & $-9,849,490,945.33062$ & \\
\hline & \multicolumn{2}{|c|}{ Maximum } & $7.33051201511 \mathrm{E}+10$ & \\
\hline
\end{tabular}




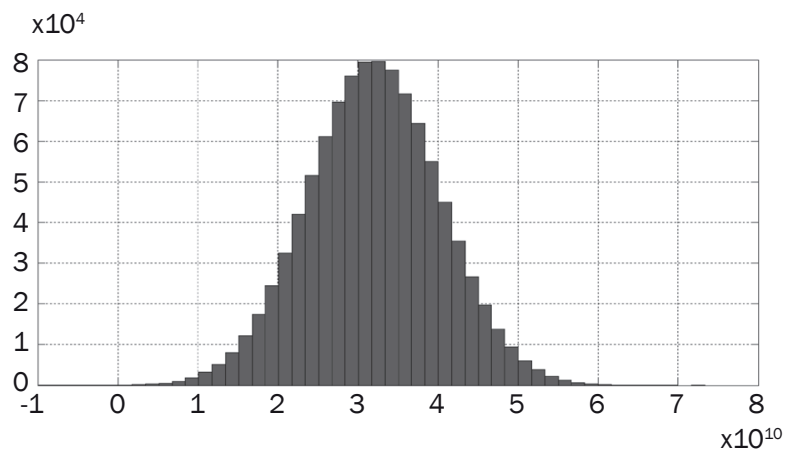

Figure 6 - Histogram of TRCE for Fars healthcare supply network

TRCE vector is calculated by Equation 27. A vector with $\mathrm{B}=1,000,000$ arrays for each probabilistic and fuzzy number based on their probability density function or fuzzy membership function is generated by MATLAB 2012a for measuring TRCE. Table 9 shows the descriptive statistics of TRCE in the Fars healthcare supply network. The average of TRCE is: $32,007,127,597.94$ grams, and the standard deviation of TRCE is: $8,261,131,178.88$.

The histogram of TRCE is illustrated in Figure 6. According to this histogram, we expect that the probability distribution function of TRCE would be normal. The Kolmogorov-Smirnov test is applied to test the normality of TRCE. Figure 7 presents the normal Q-Q plot of TRCE. It proves that the probability distribution function of TRCE is normal.

\section{CONCLUSION AND FUTURE STUDY}

In recent history, global warming has been one of the most important challenges for humanity. Understanding carbon footprint is vital in overcoming this challenge. In this paper, we provided a computational method for measuring TRCE in a healthcare supply network. In the first step, a mathematical model for designing a proper supply network under uncertainty was developed. To solve this model, we proposed a twophase algorithm based on NRGA and the PROMETHEE-II method. The statistical tests showed that the proposed algorithm has better performance in solving the model in comparison to NSGA-II and MOPSO. In the proposed algorithm, the number of solutions in the $\mathrm{Pa}$ reto front can be adjusted to be at least equal to a fixed number. This can provide more possibilities for decision-makers to obtain optimal solutions in real-world problems. In the next step, a computational method based on Monte Carlo was developed for measuring TRCE. The proposed approach was applied to the Fars healthcare supply network. After solving the model, the total cost is $\$ 1,237,447.6$, and the fuel consumption is $13,233,837.6$ liters in the planning time horizon. The probability distribution function of TRCE is normal with the mean of $32,007,127,597.94$ grams and variance of $6.8246 \mathrm{E}+19$. The obtained results confirm the efficiency of the proposed approach as a practical tool for measuring TRCE. In this research, time windows for product delivery to distribution centers and

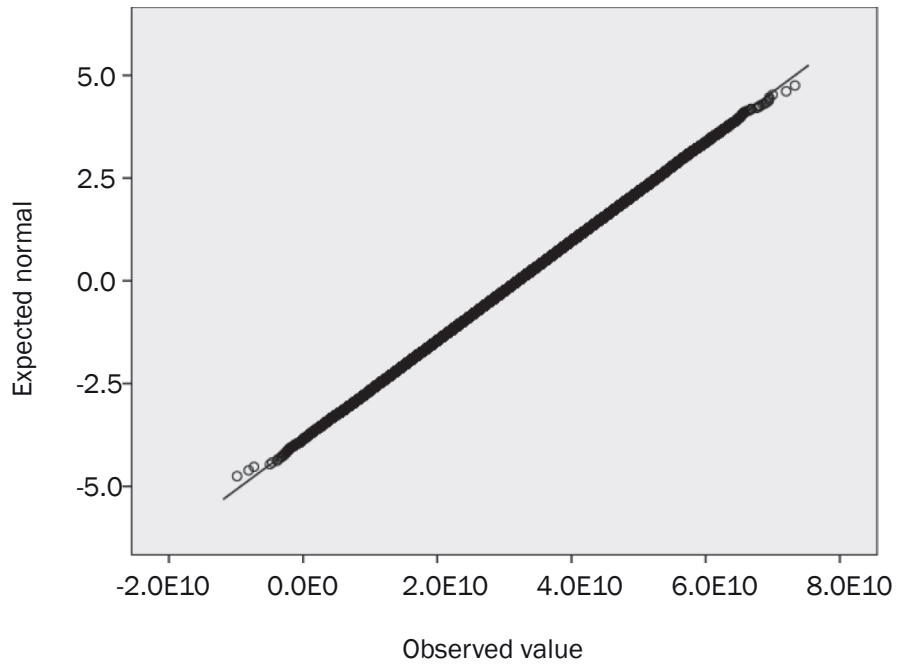

\begin{tabular}{|c|c|c|c|}
\hline \multirow{2}{*}{} & \multicolumn{3}{|c|}{ Test of normality } \\
\cline { 2 - 4 } & Statistic & df & Sig. \\
\hline TREC & 0.001 & 999999 & $0.200 *$ \\
\hline \multirow{3}{*}{ * A lower bound of true significance } \\
a Lilliefors significance correction
\end{tabular}

Figure 7 - Normal Q-Q plot of TRCE for Fars healthcare supply network 
customers are not considered. Due to the importance of time windows in pharmaceutical substance delivery, further study is still required on this topic.

\section{ACKNOWLEDGMENTS}

We would like to express our appreciation to the Iran National Science Foundation (INSF) for the financial support of this study.

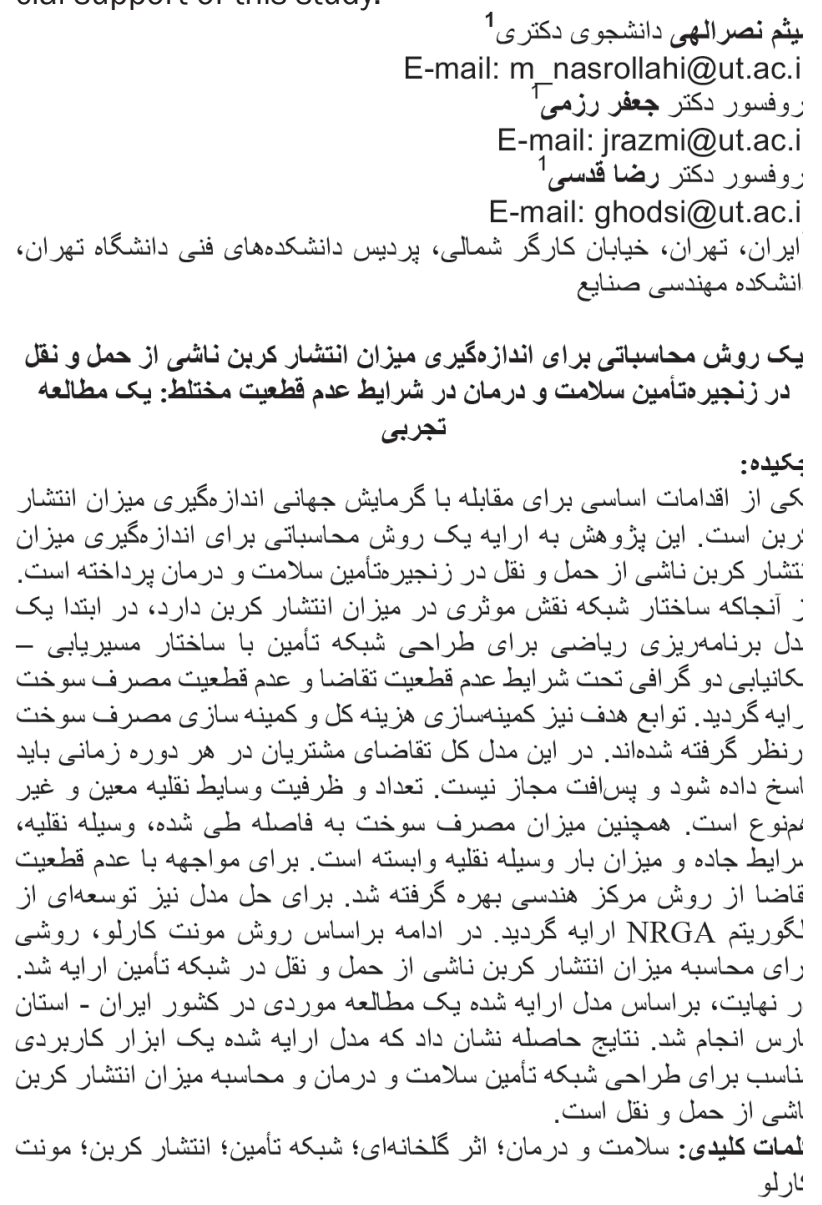

\section{REFERENCES}

[1] Martens P. Health and climate change: modelling the impacts of global warming and ozone depletion. $1^{\text {st }} \mathrm{ed}$. Routledge; 2014.

[2] Ali A, Amin SE, Ramadan HH, Tolba MF. Enhancement of OMI aerosol optical depth data assimilation using artificial neural network. Neural Computing and Applications. 2013;23(7-8): 2267-2279. Available from: https://doi.org/10.1007/s00521-012-1178-9

[3] Pachauri RK, Allen MR, Barros VR, Broome J, Cramer W, Christ R, et al. Climate Change 2014: Synthesis Report. Contribution of Working Groups I, II and III to the Fifth Assessment Report of the Intergovernmental Panel on Climate Change, 2014. Available from: https://www.ipcc.ch/report/ar5/syr

[4] Peters GP, Andrew RM, Boden T, Canadell JG, Ciais P, Le Quere C, et al. The challenge to keep global warming below $2{ }^{\circ} \mathrm{C}$. Nature Clim Change. 2013;3(1): 4-6. Available from: http://dx.doi.org/10.1038/nclimate1783
[5] Reddy PP. Causes of Climate Change. In: Climate Resilient Agriculture for Ensuring Food Security. $1^{\text {st }}$ ed. Springer; 2015. p. 17-26.

[6] Meinshausen M, Meinshausen N, Hare W, Raper SCB, Frieler K, Knutti R, et al. Greenhouse-gas emission targets for limiting global warming to $2^{\circ} \mathrm{C}$. Nature. 2009;458(7242): 1158-1162. Available from: http:// dx.doi.org/10.1038/nature08017

[7] Plambeck EL. Reducing greenhouse gas emissions through operations and supply chain management. Energy Economics. 2012;34(Suppl.1): 564-574. Available from: http://dx.doi.org/10.1016/j.eneco.2012.08.031

[8] IPCC. Mitigation of climate change: Contribution of working group III to the fourth assessment report of the Intergovernmental Panel on Climate Change. Intergovernmental Panel on Climate Change; 2007. 851 p.

[9] Mula J, Peidro D, Poler R. The effectiveness of a fuzzy mathematical programming approach for supply chain production planning with fuzzy demand. International Journal of Production Economics. 2010;128(1): 136-143. Available from: http://dx.doi.org/10.1016/ j.ijpe.2010.06.007

[10] Selim H, Ozkarahan I. A supply chain distribution network design model: An interactive fuzzy goal programming-based solution approach. International Journal of Advanced Manufacturing Technology. 2008;36(34): 401-418. Available from: https://doi.org/10.1007/ s00170-006-0842-6

[11] Acquaye A, Genovese A, Barrett J, Koh SCL. Benchmarking carbon emissions performance in supply chains. Supply Chain Management: An International Journal. 2014;19(3): 306-321. Available from: http://www.emeraldinsight.com/10.1108/SCM-11-2013-0419

[12] O'Shea SJ, Allen G, Fleming ZL, Bauguitte SJ-B, Percival CJ, Gallagher MW, et al. Area fluxes of carbon dioxide, methane, and carbon monoxide derived from airborne measurements around Greater London: A case study during summer 2012. Journal of Geophysical Research: Atmospheres. 2014;119(8): 49404952. Available from: http://doi.wiley.com/10.1002/ 2013JD021269

[13] Benjaafar S, Li Y, Daskin M. Carbon Footprint and the Management of Supply Chains: Insights From Simple Models. IEEE Transactions on Automation Science and Engineering. 2012;10(1): 99-116. Available from: https://ieeexplore.ieee.org/document/6248180

[14] Carling K, Han M, Håkansson J, Meng X, Rudholm N. Measuring transport related $\mathrm{CO} 2$ emissions induced by online and brick-and-mortar retailing. Transportation Research Part D. 2015;40: 28-42. Available from: http://dx.doi.org/10.1016/j.trd.2015.07.010

[15] Minx JC, Wiedmann T, Wood R, Peters GP, Lenzen M, Owen A, et al. Input-output analysis and carbon footprinting: an overview of applications. Economic Systems Research. 2009;21(3): 187-216. Available from: https://doi.org/10.1080/09535310903541298

[16] Jaegler A, Burlat P. Carbon friendly supply chains: a simulation study of different scenarios. Production Planning \& Control. 2012;23(4): 269-278. Available from: https://doi.org/10.1080/09537287.2011.627656

[17] Tian Y, Liu Q. The Study about the Calculation Method of Product Carbon Footprint during the Flow Manufacturing Process. Journal of Low Carbon Economy. 2014;3: 1-6. Available from: http://dx.doi.org/ 
10.12677/jlce.2014.31001

[18] Mogensen L, Kristensen T, Nguyen TLT, Knudsen MT, Hermansen JE. Method for calculating carbon footprint of cattle feeds-including contribution from soil carbon changes and use of cattle manure. Journal of Cleaner Production. 2014;73: 40-51. Available from: https:// doi.org/10.1016/j.jclepro.2014.02.023

[19] Kaydani H, Najafzadeh M, Hajizadeh A. A new correlation for calculating carbon dioxide minimum miscibility pressure based on multi-gene genetic programming. Journal of Natural Gas Science and Engineering. 2014;21(1): 625-630. Available from: https://doi.org/ 10.1016/j.jngse.2014.09.013

[20] Ryu BY, Jung HJ, Bae SH. Development of a corrected average speed model for calculating carbon dioxide emissions per link unit on urban roads. Transportation Research Part D: Transport and Environment. 2015;34: 245-254. Available from: https://doi. org/10.1016/j.trd.2014.10.012

[21] Ortmeyer TH, Pillay P. Trends in transportation sector technology energy use and greenhouse gas emissions. Proceedings of the IEEE. 2001;89(12): 18371847. Available from: http://ieeexplore.ieee.org/ stamp/stamp.jsp?tp=\&arnumber $=975921 \&$ isnum ber $=21066$

[22] Morrow WR, Gallagher KS, Collantes G, Lee H. Analysis of policies to reduce oil consumption and greenhouse-gas emissions from the US transportation sector. Energy Policy. 2010;38(3): 1305-1320. Available from: https://doi.org/10.1016/j.enpol.2009.11.006

[23] Lotfi MM, Tavakkoli-Moghaddam R. A genetic algorithm using priority-based encoding with new operators for fixed charge transportation problems. Applied Soft Computing. 2013;13(5): 2711-2726. Available from: https://doi.org/10.1016/j.asoc.2012.11.016

[24] Babazadeh A, Langerudi MF, Afkar N, Shahandashti KF. Parameter Selection In Particle Swarm Optimization For Transportation Network Design Problem. arXiv preprint arXiv:14127185. 2014. Available from: http:// arxiv.org/ftp/arxiv/papers/1412/1412.7185.pdf

[25] Jang Y-J, Jang S-Y, Chang B-M, Park J. A combined model of network design and production/distribution planning for a supply network. Computers \& Industrial Engineering. 2002;43(1-2): 263-281. Available from: http://linkinghub.elsevier.com/retrieve/pii/S0360835202000748

[26] Pontrandolfo P, Okogbaa OG. Global manufacturing: A review and a framework for planning in a global corporation. International Journal of Production Research. 1999;37(1): 1-19. Available from: https://doi.org/ 10.1080/002075499191887

[27] Wong KF, Beasley JE. Vehicle routing using fixed delivery areas. Omega. 1984;12(6): 591-600. Available from: https://doi.org/10.1016/0305-0483(84)90062-8

[28] Norouzi N, Sadegh-Amalnick M, Alinaghiyan M. Evaluating of the particle swarm optimization in a periodic vehicle routing problem. Measurement. 2015;62: 162-169. Available from: https://doi.org/10.1016/ j.measurement.2014.10.024

[29] Huang Z, Geng K. Local search for dynamic vehicle routing problem with time windows. In: Instrumentation and Measurement, Sensor Network and Automation (IMSNA), $20132^{\text {nd }}$ International Symposium on. IEEE; 2013. p. 841-4.

[30] Baldacci R, Mingozzi A, Roberti R. Recent exact algo- rithms for solving the vehicle routing problem under capacity and time window constraints. European Journal of Operational Research. 2012;218(1): 1-6. Available from: http://dx.doi.org/10.1016/j. ejor.2011.07.037

[31] Nadizadeh A, Hosseini Nasab H, Nasab HH. Solving the dynamic capacitated location-routing problem with fuzzy demands by hybrid heuristic algorithm. European Journal of Operational Research. 2014;238(2): 458-470. Available from: http://linkinghub.elsevier. com/retrieve/pii/S037722171400321X

[32] Vahdani B, Shekari DVN, Mousavi SM. Multi-objective, multi-period location-routing model to distribute relief after earthquake by considering emergency roadway repair. Neural Computing and Applications. 2016;30(3): 835-854. Available from: https://doi. org/10.1007/s00521-016-2696-7

[33] Ewbank H, Wanke P, Hadi-Vencheh A. An unsupervised fuzzy clustering approach to the capacitated vehicle routing problem. Neural Computing and Applications. 2015; 857-867. Available from: http://link.springer. com/10.1007/s00521-015-1901-4

[34] Dalfard VM, Kaveh M, Nosratian NE. Two meta-heuristic algorithms for two-echelon location-routing problem with vehicle fleet capacity and maximum route length constraints. -Neural Computing and Applications. 2013;23(7-8): 2341-2349. Available from: ttps://doi.org/10.1007/s00521-012-1190-0

[35] Escobar JW, Linfati R, Baldoquin MG, Toth P. A Granular Variable Tabu Neighborhood Search for the capacitated location-routing problem. Transportation Research Part B: Methodological. 2014;67: 344-356. Available from: https://doi.org/10.1016/j.trb.2014.05.014

[36] Hemmelmayr VC. Sequential and parallel large neighborhood search algorithms for the periodic location routing problem. European Journal of Operational Research. 2015;243(1): 52-60. Available from: https:// doi.org/10.1016/j.ejor.2014.11.024

[37] Wang F, Lai X, Shi N. A multi-objective optimization for green supply chain network design. Decision Support Systems. 2011;51(2): 262-269. Available from: http:// dx.doi.org/10.1016/j.dss.2010.11.020

[38] Srivastava SK. Green supply chain management: a state of the art literature review. International journal of management reviews. 2007;9(1): 53-80. Available from: https://ieeexplore.ieee.org/document/6852800

[39] Rahimi M, Baboli A, Rekik Y. Multi-objective inventory routing problem: A stochastic model to consider profit, service level and green criteria. Transportation Research Part E: Logistics and Transportation Review. 2017;101: 59-83. Available from: http://dx.doi. org/10.1016/j.tre.2017.03.001

[40] Marcon E, Chaabane S, Sallez Y, Bonte T, Trentesaux D. Simulation Modelling Practice and Theory A multiagent system based on reactive decision rules for solving the caregiver routing problem in home health care. Simulation Modelling Practice and Theory. 2017;74: 134-151. Available from: http://dx.doi.org/10.1016/ j.simpat.2017.03.006

[41] Mańdziuk J, Świechowski M. UCT in Capacitated Vehicle Routing Problem with traffic jams. Information Sciences. 2017;406: 42-56. Available from: https://doi.org/ 10.1016/j.ins.2017.04.020

[42] Puga MS, Tancrez J. A heuristic algorithm for solving 
large location - inventory problems with demand uncertainty. European Journal ofOperational Research. 2017;259(2): 413-423. Available from: https://doi.org/ 10.1016/j.ejor.2016.10.037

[43] Dehghani E, Behfar nima, Jabalameli MS. Optimizing location, routing and inventory decisions in an integrated supply chain network under uncertainty. Journal of Industrial and Systems Engineering. 2016;9(4):93-111. Available from: http://www.jise.ir/article_16501_0ccd46eae583b5bc10ca6437f66f71ae.pdf

[44] Nasrollahi M, Amiri AS, Razmi J, Nasrollahi H. Bullwhip Effect in Different Network Configuration. Applied Mathematics in Engineering Management and Technology. 2015;3(4): 261-267.

[45] Safaei M, Thoben KD. Measuring and evaluating of the network type impact on time uncertainty in the supply networks with three nodes. Measurement: Journal of the International Measurement Confederation. 2014;56: 121-127. Available from: http://dx.doi. org/10.1016/j.measurement.2014.06.010

[46] Rezvani S. Ranking generalized exponential trapezoidal fuzzy numbers based on variance. Applied Mathematics and Computation. 2015;262: 191-198. Available from: http://linkinghub.elsevier.com/retrieve/pii/ s0096300315004889

[47] Mousavi SM, Alikar N, Niaki STA, Bahreininejad A. Two tuned multi-objective meta-heuristic algorithms for solving a fuzzy multi-state redundancy allocation problem under discount strategies. Applied Mathematical Modelling. 2015;39(22): 6968-6989. Available from: http://linkinghub.elsevier.com/retrieve/pii/ S0307904X15001298

[48] Al Jadaan O, Rajamani L, Rao CR. Non-dominated ranked genetic algorithm for solving multi-objective optimization problems. Journal of Theoretical and Applied Information Technology. 2008; 113-118. Available from: www.jatit.org/volumes/research-papers/ Vol5No5/15Vol5No5.pdf

[49] Mousavi SM, Sadeghi J, Niaki STA, Tavana M. A bi-objective inventory optimization model under inflation and discount using tuned Pareto-based algorithms: NSGA-II, NRGA, and MOPSO. Applied Soft Computing Journal. 2016;43: 57-72. Available from: http://dx.doi. org/10.1016/j.asoc.2016.02.014

[50] Kilic HS, Zaim S, Delen D. Selecting “The Best" ERP system for SMEs using a combination of ANP and PROMETHEE methods. Expert Systems with Applications. 2015;42(5): 2343-2352. Available from: http://linkinghub.elsevier.com/retrieve/pii/S0957417414006587

[51] Athawale VM, Chakraborty S. Facility Location Selection using PROMETHEE II Method. International Conference on Industrial Engineering and Operations Management Dhaka. January 9-10; 2010.

[52] amar.sci.org.ir [Internet]. Available from: https://amar. sci.org.ir/index_e.aspx

[53] Deb K, Pratap A, Agarwal S, Meyarivan T. A fast and elitist multiobjective genetic algorithm: NSGA-II. IEEE Transactions on Evolutionary Computation. 2002;6(2): 182-197. Available from: https://ieeexplore.ieee.org/ document/996017.

[54] Pasandideh SHR, Niaki STA, Asadi K. Bi-objective optimization of a multi-product multi-period three-echelon supply chain problem under uncertain environments: NSGA-II and NRGA. Information Sciences. 2015;292: 57-74. Available from: http://dx.doi.org/10.1016/ j.ins.2014.08.068

[55] Moore J, Chapman R. Application of particle swarm to multiobjective optimization. Department of Computer Science and Software Engineering Department, Auburn University. 1999; 1-4. Available from: http://goo.gl/ NPkun

[56] Azadeh A, Ravanbakhsh M, Rezaei-Malek M, Sheikhalishahi M, Taheri-Moghaddam A. Unique NSGA-II and MOPSO Algorithms for Improved Dynamic CMS by Considering Human Factors. Applied Mathematical Modelling. 2017;48: 655-672. Available from: http://linkinghub.elsevier.com/retrieve/pii/S0307904X17301221

[57] Montgomery DC, Runger GC. Applied statistics and probability for engineers. $6^{\text {th }} \mathrm{ed}$. NJ: Wiley; 2007. 